\title{
Nonlinear Model and Qualitative Analysis for Coupled Axial/Torsional Vibrations of Drill String
}

\author{
Fushen Ren, ${ }^{1,2}$ Baojin Wang, ${ }^{1}$ Suli Chen, ${ }^{1}$ Zhigang Yao, ${ }^{1}$ and Baojun Bai ${ }^{2}$ \\ ${ }^{1}$ Department of Mechanical Science and Engineering, Northeast Petroleum University, Daqing, Heilongjiang 163318, China \\ ${ }^{2}$ Department of Petroleum Engineering, Missouri University of Science and Technology, Rolla, MO 65401, USA \\ Correspondence should be addressed to Baojun Bai; baib@mst.edu
}

Received 29 September 2015; Revised 29 November 2015; Accepted 30 November 2015

Academic Editor: Emiliano Mucchi

Copyright (c) 2016 Fushen Ren et al. This is an open access article distributed under the Creative Commons Attribution License, which permits unrestricted use, distribution, and reproduction in any medium, provided the original work is properly cited.

\begin{abstract}
A nonlinear dynamics model and qualitative analysis are presented to study the key effective factors for coupled axial/torsional vibrations of a drill string, which is described as a simplified, equivalent, flexible shell under axial rotation. Here, after dimensionless processing, the mathematical models are obtained accounting for the coupling of axial and torsional vibrations using the nonlinear dynamics qualitative method, in which excitation loads and boundary conditions of the drill string are simplified to a rotating, flexible shell. The analysis of dynamics responses is performed by means of the Runge-Kutta-Fehlberg method, in which the rules that govern the changing of the torsional and axial excitation are revealed, and suggestions for engineering applications are also given. The simulation analysis shows that when the drill string is in a lower-speed rotation zone, the torsional excitation is the key factor in the coupling vibration, and increasing the torsional stress of the drill string more easily leads to the coupling vibration; however, when the drill string is in a higher-speed rotating zone, the axial excitation is a key factor in the coupling vibration, and the axial stress in a particular interval more easily leads to the coupling vibration of the drill string.
\end{abstract}

\section{Introduction}

The drill string consists of several drill pipes, drill collars, stabilizers, and connections (crossover sub), subjected to some heavy and complex dynamic loadings caused by different sources, such as bit and drill string interactions with the formations, torque exerted by the rotary table or top drive, buckling, and misalignment. By producing different states of stress, these loads might result in excess vibrations and lead to failure of the drilling tools. Moreover, rotation of the rotary table or top drive on the surface might be transformed into a turbulent movement in the downhole. Three forms of vibrations that have been identified for the drill string are axial, torsional, and lateral vibrations, as shown in Figure 1 [1].

The coupling vibration of the drill string can lead to severe vibration, and this energy boosts the amplitude of the string vibration, increases bending and impacts with the borehole, and leads to the early fatigue of tools and the reduction of bit life. Moreover, impacts with the borehole wall tend to form an overgauge hole or produce problems with the directional control of the well and also increase the surface torque [2]. An analytical approach has been the basis for early analyses $[3,4]$. Yigit and Christoforou $[5,6]$ modeled the drill string based on the assumed mode method. Their models account for the coupling between the axial and transverse vibrations [5] and between the torsional and transverse vibrations [6]. Khan [7] employs the FDM (finite difference method) to solve the axial and torsional vibrations of the drill string, neglecting the added mass and damping effects. Shyu [8] studied the coupling between the axial and lateral vibrations and the whirling of the drill string using FDM. Christoforou and Yigit [9] extended their previous work to analyze the coupled axial/torsional/flexural vibrations of drill strings by means of a simplified, lumped parameter differential system. Trindade et al. [10] introduced a nonlinear, continuous beam model to study the influence of geometrical nonlinearity in coupled axial/transversal vibrations of drill strings, which has shown that the nonlinear model has strong quantitative and qualitative discrepancies with respect to a linear model. 


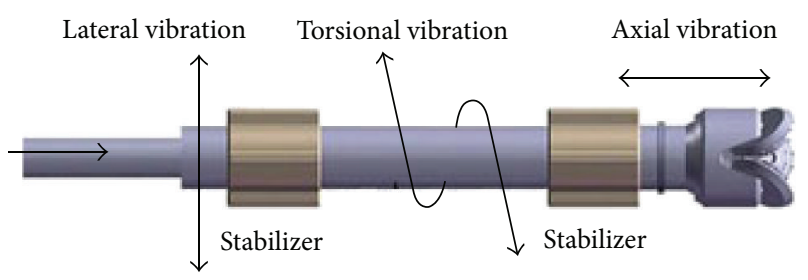

FIGURE 1: Three forms of drill string vibration.

In accord with the geometric nonlinear characteristics of drill strings, and by adopting the combination of nonlinear dynamics and FEM (finite element method), Sampaio et al. [11] established the mathematical coupling model of axial and torsional vibrations by comparing it with a linear model, finding that the nonlinear model more accurately reflected the features of the vibration of the drill string. Hakimi and Moradi [12] introduced a differential quadrature method to analyze the vibration of the drill string. Ren et al. [13] and Ren and Yao [14], taking into account the flexible and geometric large deformation of the drill string, established the mathematical model of bending nonlinear vibration for the horizontal well. In addition, taking into account other factors of drill-string vibration, scholars have carried out some research, such as on the (a) displacement and force of the drill bit [15], (b) critical speed of the drill string [16], (c) nonlinear collision and friction contact between the drill string and the borehole wall $[17,18]$, (d) theory and experiments about coupled solids-liquids [19], and (e) the weight on bit (WOB) and rotation speed of the drill string [20-22]. Gonçalves and Del Prado [23] analyzed the nonlinear vibrations and dynamic instability of axially loaded circular, cylindrical shells under both static and harmonic forces, based on Donnell shallow shell equations. The most dangerous region in parameter space is obtained, and the triggering mechanisms associated with the stability boundaries are identified [23]. Based on the Sanders-Koiter theory, Strozzi and Pellicano [24] analyzed the nonlinear vibrations of functionally graded, circular, cylindrical shells and found that when these shells that were having an actual hardening response were simulated with an insufficient expansion, their behavior could appear spuriously softening.

Based on the specific problem of the coupled vibration of the drill string, scholars usually analyze the drill string to find the relationship between the drilling process parameters and the modal shapes and then change the drilling parameters to avoid the resonance of the drill string, which is a very practical control method; however, the key factor is to discover the relationship between the key dynamics parameters and the coupled vibrations of the drill string. Considering the complexity of the practical dynamics of the drill string system and the comprehensiveness of the quantitative analysis directly, this study employs the dimensionless method to investigate the mechanism of the coupled vibration of the drill string qualitatively. This will reveal which key factors affect the coupled vibration and how they function, which can be a basis for the quantitative analysis of the coupling vibration of the drill string.

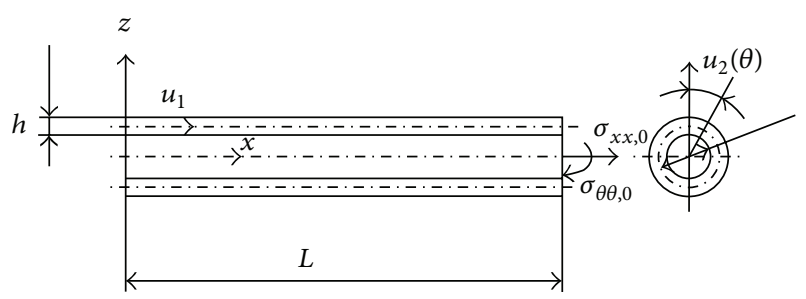

FIGURE 2: The mechanical model of the rotation, flexible shell.

\section{Nonlinear Dynamics Motion Equation}

During the process of drilling, the transverse vibration of the drill string, which is intense at the bit in the bottom of the well and attenuates quickly along the drill string, mainly contributes to the bottom hole assembly (BHA); however, the axial and torsional vibration affects the entire drill string.

In addition, several stabilizers support the lower portion of the drill string and absorb most transverse vibration energy. In other words, the transverse motion of the stabilized section mainly contributes to the transverse dynamics at the bit. The drill collars are assumed to be rigid for torsional vibrations; that is to say, the torsional deformations are assumed to take place only in the drill pipe, which can be justified since the drill collars are much stiffer than the drill pipe in torsion. Therefore, the transverse vibration of the BHA is decoupled from the upper segments of the drill string, and the entire drill string is assumed to be fixed at the top and free at the bit for the axial and torsional motion [9].

Based on the above analyses, ignoring the transverse vibration of the drill string, this work only analyzes the mechanism of the coupled axial and torsional vibration of the upper portion of the BHA. Here, assuming the centerline of the shell before deformation as the axis, the drill string is simplified to a flexible rotation shell instead of simply a supported beam, which will ignore most torsional vibration. The dynamics model is shown in Figure 2, where $u_{1}$ and $u_{2}$ are the displacement of axial $x$ and circumferential $u$, respectively; $h$ is the thickness of the drill string; $L$ is the length of the drill string; $\sigma_{x x, 0}$ is the initial axial stress, and $\sigma_{\theta \theta, 0}$ is the initial torsional stress.

To facilitate the calculation of the drill string strain, select the arbitrary point displacement of the drill string as follows [25]:

$$
\begin{aligned}
& u_{1}=u, \\
& u_{2}=v+\frac{z}{R} v,
\end{aligned}
$$

where $u$ and $v$ are arbitrary axial and circumferential displacements of the drill string on the middle surface $z=$ 0 , respectively; and $R$ is the middle radius of the drill string.

Since the drill string cannot be thin, and the tangential displacements $u$ and $v$ of the drill string are not small, the Flugge-Lur'e-Byrne nonlinear shell theory is selected, in which two hypotheses are removed from Donnell's nonlinear shell theory [26] in order to obtain more accurate nonlinear 
shell theories. One is the thinness assumption, and the other is that the tangential displacements are infinitely small, which leads to neglecting the nonlinear terms that depend on $u$ and $v$.

Based on the nonlinear shell theory [25], the relationship of the stress/displacement at any point on the drill string can be expressed by

$$
\begin{aligned}
\varepsilon_{x x}= & \frac{\partial u}{\partial x}+\frac{1}{2}\left(\frac{\partial u}{\partial x}\right)^{2}+\frac{1}{2}\left(\frac{\partial v}{\partial x}\right)^{2}+z \frac{1}{R}\left(\frac{\partial v}{\partial x}\right)^{2} \\
\varepsilon_{\theta \theta}= & \frac{1}{R} \frac{\partial v}{\partial \theta}+\frac{1}{2 R^{2}}\left(\frac{\partial u}{\partial \theta}\right)^{2}+\frac{1}{2 R^{2}}\left(\frac{\partial v}{\partial \theta}\right)^{2}+\frac{1}{2 R^{2}} v^{2} \\
& -\frac{1}{R^{3}} z\left(\frac{\partial u}{\partial \theta}\right)^{2} \\
\varepsilon_{x \theta}= & \frac{\partial v}{\partial x}+\frac{\partial u}{R \partial x}+\frac{1}{2 R^{2}}\left(\frac{\partial u}{\partial \theta}\right)^{2}+\frac{1}{R} \frac{\partial u}{\partial x} \frac{\partial u}{\partial \theta} \\
& +\frac{1}{R} \frac{\partial v}{\partial x} \frac{\partial v}{\partial \theta}+z \kappa_{x \theta}
\end{aligned}
$$

where

$$
\kappa_{x \theta}=\frac{1}{R} \frac{\partial v}{\partial x}-\frac{1}{R^{2}} \frac{\partial u}{\partial \theta}-\frac{1}{R^{2}} \frac{\partial u}{\partial x} \frac{\partial u}{\partial \theta}-\frac{1}{R^{2}} \frac{\partial v}{\partial x} \frac{\partial v}{\partial \theta},
$$

where $\varepsilon_{x x}$ and $\varepsilon_{\theta \theta}$ are linear strain, $\varepsilon_{x \theta}$ is shear strain, and they are the dimensionless physical quantities. Here, (2a), $(2 \mathrm{~b})$, and (2c) make up most of the nonlinear term, which avoids the nonlinear coupled axial and torsional terms in the following analyses due to oversimplification.

Analogous to the case of plane stress, the stress in thickness of the drill string is neglected [27]. Taking into account the single material of the drill string, neglecting the geometric imperfections, and subject to the initial axial and torsional stress, the relationship between stress and strain can be written as

$$
\begin{aligned}
& \sigma_{x x}=E_{1}\left(\varepsilon_{x x}+\kappa \varepsilon_{\theta \theta}\right)+\sigma_{x x, 0}, \\
& \sigma_{\theta \theta}=E_{1}\left(\varepsilon_{\theta \theta}+\kappa \varepsilon_{x x}\right)+\sigma_{\theta \theta, 0}, \\
& \sigma_{x \theta}=E_{2} \varepsilon_{x \theta},
\end{aligned}
$$

where $E_{1}=E /\left(1-\kappa^{2}\right), E_{2}=E / 2(1+\kappa), \kappa$ is Poisson's ratio, and $E$ is the elasticity modulus.
Based on (2a), (2b), and (2c) and (4a), (4b), and (4c), according to Hamilton's principle, the dynamic equation of the partial differential can be obtained as follows:

$$
\begin{aligned}
\rho \ddot{u}= & \left(\frac{1}{2} R h \sigma_{x x, 0} E_{1}+R h \kappa E_{1} \varepsilon_{\theta \theta}+R h v E_{1} \varepsilon_{x x}\right) \frac{\partial^{2} u}{\partial x^{2}} \\
& +\left(\frac{h \sigma_{\theta \theta, 0}}{2 R}+\frac{h E_{1} \varepsilon_{\theta \theta}}{R}+\frac{h E_{1} \kappa \varepsilon_{x x}}{R}\right)\left(\frac{\partial^{2} u}{\partial \theta^{2}}\right) \\
& -\frac{C_{1}}{2 \pi L} \dot{u}+\frac{1}{2} R h \frac{\partial \sigma_{x x, 0}}{\partial x} \\
& +R h E_{1}\left(\frac{\partial \varepsilon_{x x}}{\partial x}+v \frac{\partial \varepsilon_{\theta \theta}}{\partial x}\right)+\frac{h}{2 R} \frac{\partial \sigma_{x x, 0}}{\partial x^{2}} \frac{\partial u}{\partial x} \\
& +\frac{h E_{1}}{R} \frac{\partial \varepsilon_{\theta \theta}}{\partial \theta} \frac{\partial u}{\partial \theta}+R h \kappa E_{1} \frac{\partial \varepsilon_{\theta \theta}}{\partial x} \frac{\partial u}{\partial x} \\
& +\frac{h \kappa E_{1}}{R} \frac{\partial \varepsilon_{\theta \theta}}{\partial \theta} \frac{\partial u}{\partial \theta}+R h E_{1} \frac{\partial \varepsilon_{\theta \theta}}{\partial x} \frac{\partial u}{\partial x}, \\
\rho \ddot{v}= & \left(\frac{1}{2} R h \sigma_{x x, 0}+R h v E_{1} \varepsilon_{\theta \theta}+R h E_{1} \varepsilon_{x x}\right) \frac{\partial^{2} v}{\partial x^{2}} \\
& +\left(\frac{h \sigma_{\theta \theta, 0}}{2 R}+\frac{h E_{1} \varepsilon_{\theta \theta}}{R}+\frac{h E_{1} v \varepsilon_{x x}}{R}\right)\left(\frac{\partial^{2} v}{\partial \theta^{2}}\right) \\
& -\frac{1}{2 \pi L} C_{2} \dot{v}+\frac{h}{2} \frac{\partial \sigma_{\theta \theta, 0}}{\partial \theta}+h E_{1}\left(v \frac{\partial \varepsilon_{x x}}{\partial \theta} \frac{\partial \varepsilon_{\theta \theta}}{\partial \theta}\right) \\
& +\frac{h}{2 R} \frac{\partial \sigma_{\theta \theta, 0}}{\partial \theta} \frac{\partial v}{\partial \theta}+\frac{h v E_{1}}{R} \frac{\partial \varepsilon_{\theta \theta}}{\partial \theta} \frac{\partial v}{\partial \theta} \\
& +R h v E_{1} \frac{\partial \varepsilon_{\theta \theta}}{\partial x} \frac{\partial v}{\partial x}+\frac{h E_{1}}{R} \frac{\partial \varepsilon_{\theta \theta}}{\partial \theta} \frac{\partial v}{\partial \theta} \\
& +R h E_{1} \frac{\partial \varepsilon_{x x}}{\partial x} \frac{\partial v}{\partial x}-\frac{h v E_{1}}{R} \varepsilon_{\theta \theta}+\frac{R h}{2} \frac{\partial \sigma_{x x, 0}}{\partial x} \frac{\partial v}{\partial x} \\
& \frac{h}{2} \\
& \frac{\partial}{2}
\end{aligned}
$$

where $\rho$ is the density of the drill string, $I=\int_{-1 / 2}^{1 / 2} \rho d z$ is the rotary inertia, and $C_{1}$ and $C_{2}$ are the damping coefficients of the first modal and the second modal, respectively. [28]

The modals of axial and torsional vibration are given as

$$
\begin{aligned}
& u=w_{1}(t) \sin \left(\frac{\pi x}{2 L}\right) \cos \theta, \\
& v=w_{2}(t) \cos \left(\frac{2 \pi x}{L}\right) \sin \theta .
\end{aligned}
$$

In the modals of the axial vibration and torsional vibration, the number of longitudinal half-waves was equal to one and two, respectively. In (6), when $x=0$ then $u=0$; when $x=L$, then $u$ became the extreme value; when $x=0$ or $x=L$ then $v$ got the extreme value, all of which meet the actual displacement boundary conditions of the drill string. Substituting (6) into (2a), (2b), and (2c), and then substituting the result into (4a), (4b), and (4c), produce $\sigma_{x x, x=0}=\sigma_{x x, 0}$ and 
$\sigma_{\theta \theta, x=0}=\sigma_{\theta \theta, 0}$, which account for the boundary conditions of the force.

Using the Galerkin method to disperse (5a) and (5b), substituting (6) into (5a) and (5b), both sides of (5a) and (5b) are multiplied by the mode of the right side of (6), integrated in the circumferential and thickness direction. Making use of modal orthogonality, the motion equation of the middle surface displacement is obtained as follows:

$$
\begin{aligned}
\ddot{w}_{1}= & a_{1} C_{1} \dot{w}_{1}+\frac{R h \sigma_{x x, 0}}{2 L \rho}-\frac{h \sigma_{\theta \theta, 0}}{2 \rho R} w_{1}-a_{2} w_{1}-a_{3} w_{2} \\
& +a_{4} w_{1} w_{2}^{2}-a_{5} w_{1}^{3}, \\
\ddot{w}_{2}= & a_{1} C_{2} \dot{w}_{2}-a_{6} w_{1}+\frac{1}{\rho} \frac{h \sigma_{\theta \theta, 0}}{R} w_{2}+a_{7} w_{2} w_{1}^{2}-a_{8} w_{2}^{3},
\end{aligned}
$$

where $a_{1}, a_{2}, a_{3}, a_{4}, a_{5}, a_{6}, a_{7}$, and $a_{8}$ are the constant coefficients, as listed in the Appendix. From (7a) and (7b), we know that the vibration is a nonlinear, coupled equation of axial and torsional vibration and that unilaterally taking into account the single direction of the vibration is obviously much too simplified to describe the actual vibration. The axial stress, as external excitation, directly affects the dynamics response. The torsional stress $\sigma_{\theta \theta, 0}$, as parameter excitation, affects the vibration by changing the axial stiffness, thereby affecting the natural frequency of the drill string. Assuming the axial and torsional excitation frequencies are integer times of the rotation frequency of the drill string, the equation itself will have two linear natural frequencies. Due to the existence of the coupling and nonlinear terms, there is a great difference between the actual vibration frequency and the linear, natural frequency. In addition, subharmonic resonance, superharmonic resonance, bifurcation, and chaos phenomena are possible in the vibration system with the parameters changing and the energy translating between the modals.

\section{Nonlinear Dynamics Average Equation}

To facilitate the analysis, replace the coefficients in (7a) and (7b) by $a_{i}, b_{j}$ and use the dimensionless transformation as follows (in the following dimensionless equation, the asterisk was removed for the convenience of expression):

$$
\begin{aligned}
x_{1}^{*} & =\frac{x_{1}}{L}, \\
x_{2}^{*} & =\frac{x_{2}}{L}, \\
t^{*} & =\frac{R}{L^{2}} \sqrt{\frac{E}{\rho}} t, \\
\sigma_{x x, 0}^{*} & =\frac{\sigma_{x x, 0}}{E}, \\
\sigma_{\theta \theta, 0}^{*} & =\frac{\sigma_{\theta \theta, 0}}{E} .
\end{aligned}
$$

The multiscale transformation is employed as follows:

$$
\begin{aligned}
& a_{i} \longrightarrow \varepsilon a_{i}, \\
& b_{j} \longrightarrow \varepsilon b_{j}, \\
& \quad i \neq 1, j \neq 2,
\end{aligned}
$$

where $\varepsilon$ is a small parameter used as a perturbation parameter for determining the approximate solution for the motion of the drill string [22].

Substituting (9) into (7a) and (7b), one can obtain a motion equation that includes the small parameter $\varepsilon$. Here, assume the form of the equation as follows:

$$
x_{i}(t, \varepsilon)=y_{i 0}\left(T_{0}, T_{1}\right)+\varepsilon y_{i}\left(T_{0}, T_{1}\right)+\cdots \quad(i=1,2),
$$

where $T_{0}=t$ and $T_{1}=\varepsilon t$.

Here, the differential operators are employed as in the following form:

$$
\begin{gathered}
\frac{d}{d t}=\frac{\partial}{\partial T_{0}} \frac{\partial T_{0}}{\partial t}+\frac{\partial}{\partial T_{1}} \frac{\partial T_{1}}{\partial t}+\cdots=D_{0}+\varepsilon D_{1}+\cdots \\
\frac{d^{2}}{d t^{2}}=\left(D_{0}+\varepsilon D_{1}+\cdots\right)^{2}=D_{0}^{2}+2 \varepsilon D_{0} D_{1}+\cdots
\end{gathered}
$$

where $D_{0}=\partial / \partial T_{0}$ and $D_{1}=\partial / \partial T_{1}$.

Taking into account the principal parameter resonance and 2:1 internal resonance, the resonance relationship can be expressed as follows:

$$
\begin{aligned}
& \omega_{1}^{2}=4 \omega^{2}+\varepsilon \sigma_{1}, \\
& \omega_{2}^{2}=\omega^{2}+\varepsilon \sigma_{2},
\end{aligned}
$$

where $\omega_{1}$ and $\omega_{2}$ are the axial and torsional linear natural frequencies, respectively.

Taking into account the vibration response caused by the axial and torsional excitation in the case of the above resonance, the dimensionless axial and torsional excitation in the frequency domain can be expanded into the following form, including the two resonance frequencies [29]:

$$
\begin{aligned}
& \sigma_{x x, 0}=q_{1} e^{i t}+\bar{q}_{1} e^{-i t}+q_{2} e^{2 i t}+\bar{q}_{2} e^{-i t}, \\
& \sigma_{\theta \theta, 0}=q_{3} e^{i t}+\bar{q}_{3} e^{-i t}+q_{4} e^{2 i t}+\bar{q}_{4} e^{-i t},
\end{aligned}
$$

where $q_{1}$ and $q_{2}$ are the amplitude of the low frequency and high frequency of the initial, axial stress, respectively; and $q_{3}$ and $q_{4}$ are the amplitude of the low and high frequencies of the initial, torsional stress, respectively.

Substituting (8)-(12) into (7a) and (7b) and comparing the same step coefficient of the small parameter $\varepsilon$ on both sides of the equations, one obtains a differential equation in the following form:

For $\varepsilon^{0}$

$$
D_{0}^{2} y_{10}+4 y_{1}=0
$$




$$
\begin{aligned}
& \text { For } \varepsilon^{1} \\
& \qquad D_{0}^{2} y_{20}+y_{2}=0
\end{aligned}
$$

The plural form solutions of (14a) and (14b) can be expressed as

$$
\begin{aligned}
& y_{10}=A_{1}\left(T_{1}\right) e^{2 i t}+\bar{A}_{1}\left(T_{1}\right) e^{-2 i t}, \\
& y_{20}=A_{2}\left(T_{1}\right) e^{i t}+\bar{A}_{2}\left(T_{2}\right) e^{-i t},
\end{aligned}
$$

where $\bar{A}_{1}$ and $\bar{A}_{2}$ are the conjugation of $A_{1}$ and $A_{2}$, respectively. The plural solutions of $A_{1}$ and $A_{2}$ are formed as follows:

$$
\begin{aligned}
& A_{1}=\frac{1}{2} x_{1}+\frac{1}{2} i x_{2}, \\
& A_{2}=\frac{1}{2} x_{3}+\frac{1}{2} i x_{4},
\end{aligned}
$$

where $x_{1}, x_{2}, x_{3}$, and $x_{4}$ are the projections of the vibration vector on the complex plane, which is equal to the vibration vector described as the amplitude and the phase.

Substituting (15a) and (15b) into (13a) and (13b), one obtains the motion equation with the small parameter $\varepsilon$; then, making the long term equal to zero, one obtains the averaging equation in the rectangular coordinate as follows:

$$
\begin{aligned}
\dot{x}_{1}= & -\frac{1}{2} a_{9} x_{1}-\frac{1}{8} a_{10} x_{2}\left(x_{3}^{2}+x_{4}^{2}\right) \\
& +\frac{3}{16} a_{11} x_{2}\left(x_{1}^{2}+x_{2}^{2}\right), \\
\dot{x}_{2}= & -\frac{1}{2} a_{9} x_{2}-\frac{1}{8} a_{10} x_{1}\left(x_{3}^{2}+x_{4}^{2}\right) \\
& -\frac{3}{16} a_{11} x_{1}\left(x_{1}^{2}+x_{2}^{2}\right)-\frac{1}{2} q_{2}, \\
\dot{x}_{3}= & -\frac{1}{2} a_{12} x_{3}+\frac{1}{2} a_{13} x_{4}+\frac{1}{4} a_{14} x_{4}\left(x_{1}^{2}+x_{2}^{2}\right) \\
& +\frac{3}{8} a_{15} x_{4}\left(x_{3}^{2}+x_{4}^{2}\right), \\
\dot{x}_{4}= & -\frac{1}{2} a_{12} x_{4}-\frac{1}{2} a_{13} x_{3}-\frac{1}{4} a_{14} x_{3}\left(x_{1}^{2}+x_{2}^{2}\right) \\
& -\frac{3}{8} a_{15} x_{3}\left(x_{3}^{2}+x_{4}^{2}\right)-q_{3},
\end{aligned}
$$

where $a_{9}, a_{10}, a_{11}, a_{12}, a_{13}, a_{14}$, and $a_{15}$ are the constant coefficients, listed in the Appendix.

The change rules for the amplitude and phase angles in the motion equation are found in (17a), (17b), (17c), and (17d) using the form of the differential equation. We find that $q_{1}$ and $q_{4}$ have disappeared in (17a), (17b), (17c), and (17d), and the parameters that can affect the dynamics response are only $q_{2}$ and $q_{3}$. We also know that $q_{2}$ is the high-frequency item of the initial axial excitation, and $q_{3}$ is the low-frequency item of the initial, torsional excitation, corresponding to the dynamic response of the drill string in low- and high-rotation speed areas, respectively. So, we try to reveal relationships between the two parameters with the coupling vibration of the drill string by numerical simulation.

\section{Numerical Simulation and Qualitative Analysis}

In the present section, the numerical simulation results obtained from using the proposed model are discussed for the upper portion of the BHA. The Runge-Kutta-Fehlberg method with adaptive steps is employed to perform the simulations, aiming at obtaining the dynamic response of the coupled axial and torsional vibration in the case of resonance. The geometric properties of the upper segment are the length $L=1050 \mathrm{~m}$, the middle diameter $R=0.1057 \mathrm{~m}$, the thickness $h=0.0171 \mathrm{~m}$, Poisson's ratio $\kappa=0.26$, the elastic modulus $E=210 \mathrm{GPa}$, the density $\rho=7850 \mathrm{~kg} / \mathrm{m}^{3}$, and the damping coefficients, $C_{1}$ and $C_{2}$, calculated from the considerations of Spanos et al. [30]. The representative simulation results are shown along with the changes in $q_{2}$ and $q_{3}$.

4.1. Torsional Excitation. The Runge-Kutta-Fehlberg method is employed to analyze the average of (17a), (17b), (17c), and (17d), and bifurcations of the system under exciting forces are obtained as shown in Figure 3.

From the bifurcation, along with the change in torsional excitation $q_{3}$, the response of the coupled axial and torsional vibrations progresses through a cycle from periodic motion to doubling periodic motion, to periodmultiplying motion, to quasiperiodic motion, while exhibiting this unique phenomenon of nonlinear dynamics bifurcation. When the coupled vibration response is quasiperiodic motion, the amplitude of the drill string is obviously higher than the period motion. With increasing amplitude of the excitation, the responses change from quasiperiodic motion to periodic motion; the amplitude of the vibration does not increase. Instead, it decreases to a certain extent, which is different from the results of the linear analysis method.

By only increasing the torsional excitation until $q_{3}=$ 7.24 (see Figure 3) and leaving other initial conditions and parameters the same, this creates the periodic responses shown in Figure 4.

When $q_{3}=7.26$, the amplitude of the system increases correspondingly accordingly. The period-doubling responses of system are shown in Figure 5.

When $q_{3}=7.5$, the phase diagram of the coupled vibration changes; the jumping phenomenon is more obvious; present period-multiplying responses are shown in Figure 6.

By increasing the value of $q_{3}$ so that $q_{3}=7.68$, the qualitative nature of the system response changes, presenting corresponding quasiperiodic motions, as shown in Figure 7. This shows that new, similar trajectories are derived from the original trajectories of the phase diagram, and they represent multifrequency vibration characteristics in the oscillogram and vibration frequencies that are close to the state of continuous change. Then, the system vibration is in a state between the period vibration and the chaotic vibration qualitatively; the frequency bandwidth of the coupled vibration also increases; the chaotic motions of the drill string are more likely to occur, which leads to violent vibration of the drill string. 


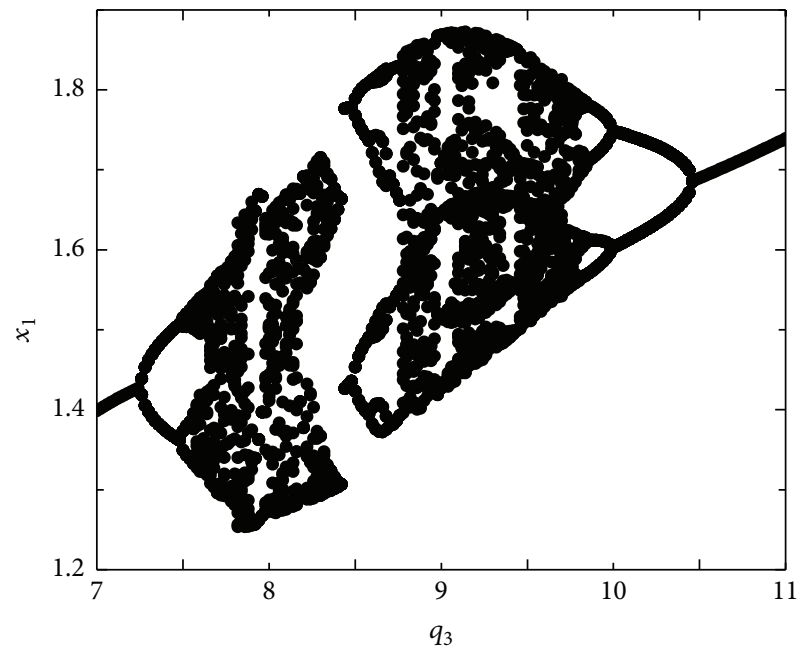

(a) Bifurcation diagram of the axial modal

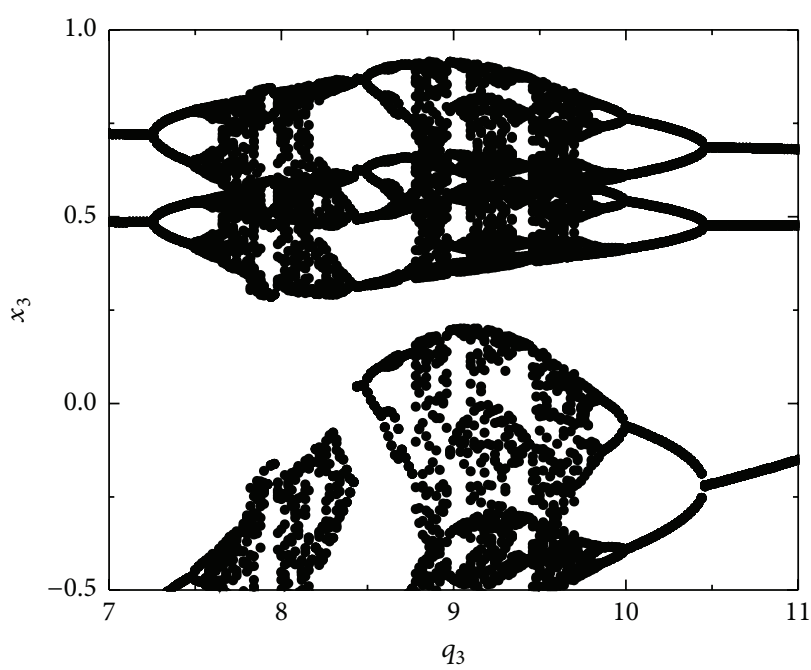

(b) Bifurcation diagram of the torsional modal

FIGURE 3: Bifurcations of the system under torsional excitation.

It is well-known that the torsional vibration of the drill string is mainly generated from the rotational speed change of the bit when breaking rock intermittently. The excitation frequency is related to the rotation speed, stiffness of the drill string, and characteristics of the rock. The higher the rock hardness, the bigger the torsional stress and the greater the torsional amplitude. We know from (17a), (17b), (17c), and $(17 \mathrm{~d})$ that torsional stress strongly affects the coupling vibration when in low-frequency excitation, but when in high-frequency excitation, the torsional stress does not effectively contribute to the coupling vibration. So, in the practical drilling process, when the drill string is in a high-rotation speed zone, the torsional stress will not lead to coupling vibration; however, when the drill string is in a low-rotation speed zone, more attention should be paid to the torsional stress and appropriate drilling process parameters should be adopted to reduce the torsional stress, especially when stickslip vibration occurs. This is necessary because, at this time, the drill string is in low torsional excitation and large torsional stress, where it is more prone to produce a coupling vibration of the drill string, as suggested by Christoforou and Yigit [9].

Based on the above simulation analysis, we also found that torsional excitation will affect both torsional and axial vibration simultaneously. Torsional and axial vibration are similar qualitatively and in the nature of the vibration and are synchronous in form, proving that energy can transfer between the torsional and the axial vibration modal.

4.2. Axial Excitation. The above analysis accounts for the impact of torsional excitation on the coupling of the axial and torsional vibrations. Here, the impact of axial excitation will be investigated.

The bifurcation diagram (Figure 8) shows the preliminary resonance tendency. The system undergoes a loop from chaos to periodic motion, then to period-three motion, then to period-multiplying, and back to chaos, showing the nonlinear dynamic phenomenon of the period-doubling bifurcation and chaos.

Increasing axial excitation until $q_{2}=0.5025$ and keeping the remaining other initial conditions and parameters unchanged, the system prevents period-doubling responses as shown in Figure 9.

When $q_{2}=0.635$, the system presents period-three responses as shown in Figure 10.

When $q_{2}=0.7725$ the phase diagram changes drastically and presents a jumping phenomenon; then, the system responds chaotically, as shown in Figure 11.

When $q_{2}=0.79$ the qualitative nature of the coupling vibration of the drill string changes; the present perioddoubled responses are shown in Figure 12. Here, the original phase trajectory of the chaotic motion (Figure 11) contracts for two trajectories and presents vibration characteristics of frequency-doubling in the phase diagram. The system vibration turns from chaotic vibration into doubling periodic motion, and the stability of the system increases.

As can be seen from the above qualitative analysis of the axial excitation of the coupling vibration, we find the same phenomenon as in the torsional excitation analysis for the coupling vibration, namely, that axial excitation affects both torsional and axial vibration simultaneously and is similar qualitatively and also synchronous in form.

Along with the increase in the axial excitation, the system coupling vibration turns from period-doubling to periodthree, to chaotic, and, finally, to period-doubling. So, the axial excitation parameter leads to a coupling vibration in some special zone. In the process of practical drilling, the axial jump mainly contributes to the axial excitation. The higher the rotation speed, the higher the excitation frequency. The larger the WOB becomes, the larger both the axial amplitude and the axial stress will be. We know from (17a), (17b), (17c), and (17d) that the axial excitation contributes to the coupling vibration when the drill string is in a high-rotation speed zone. Therefore, in the process of automation drilling with 


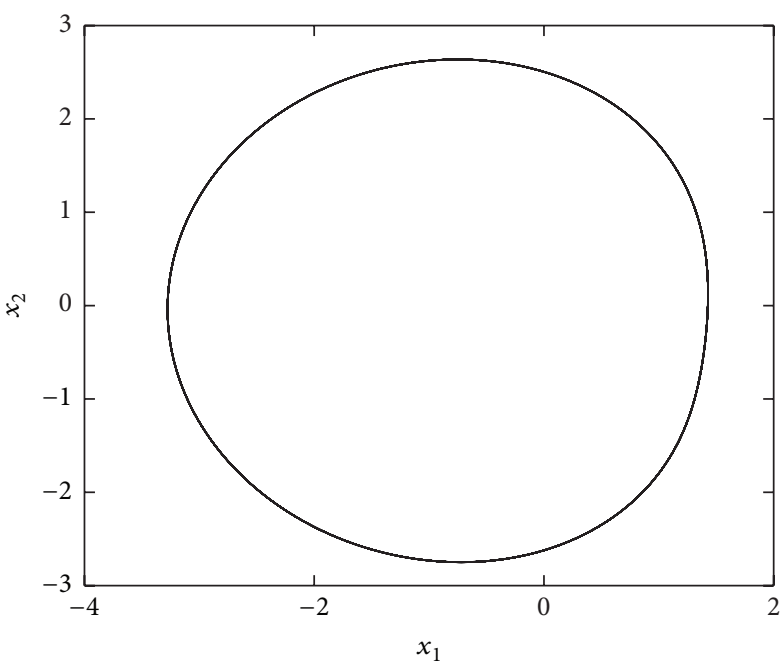

(a) Phase diagram of the axial modal

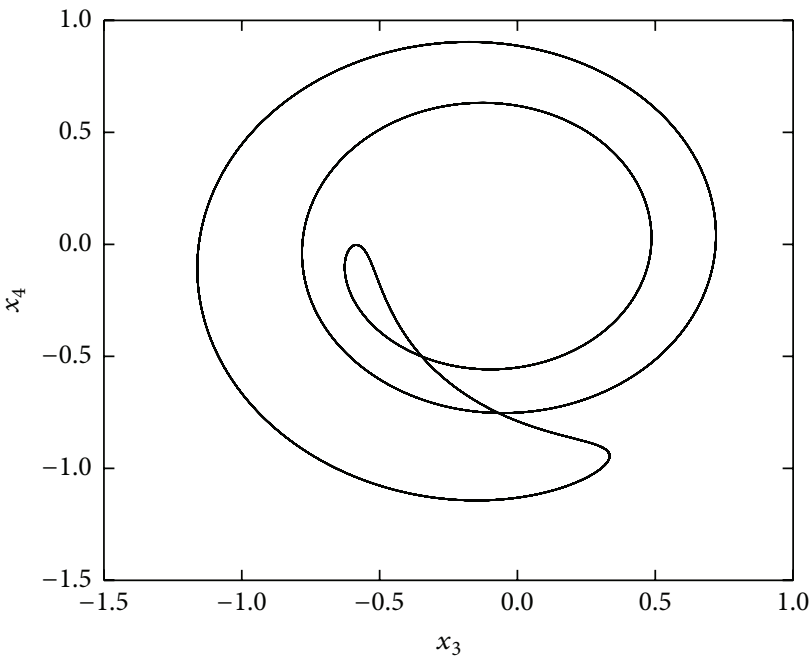

(c) Phase diagram of the torsional modal

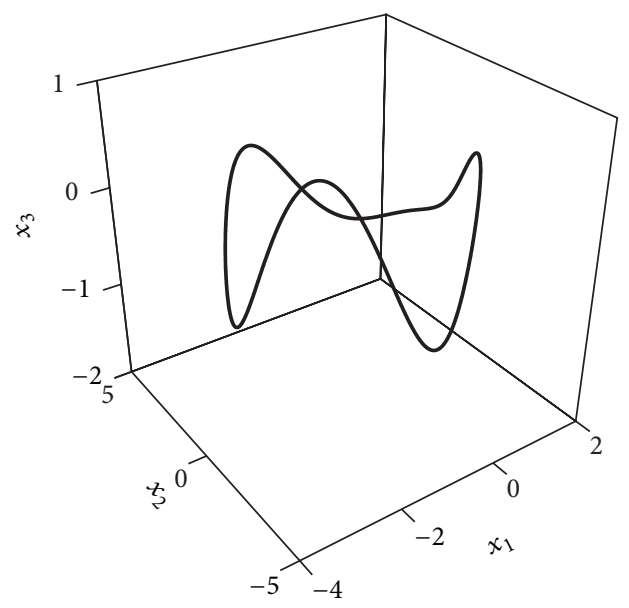

(e) Three-dimensional phase diagram

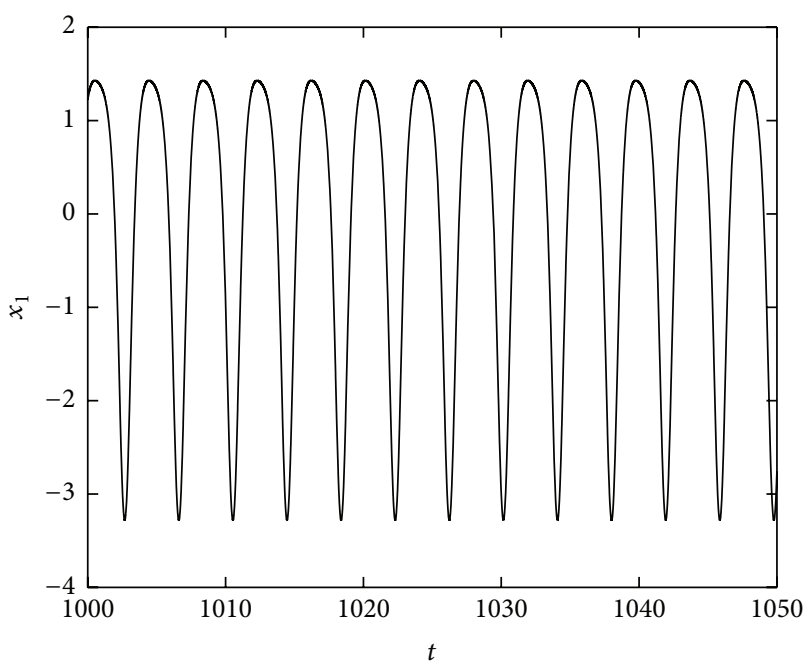

(b) Oscillogram of the axial modal

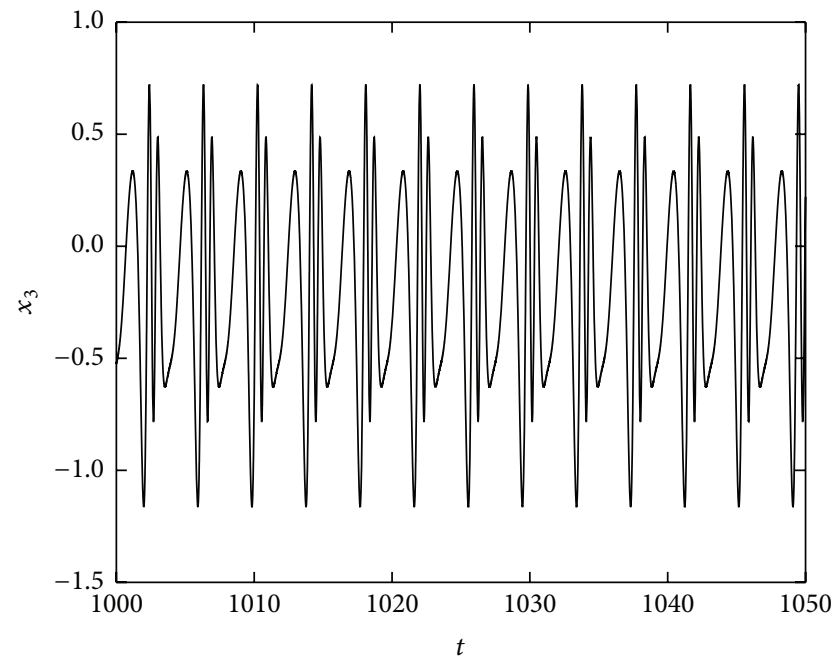

(d) Oscillogram of the torsional modal

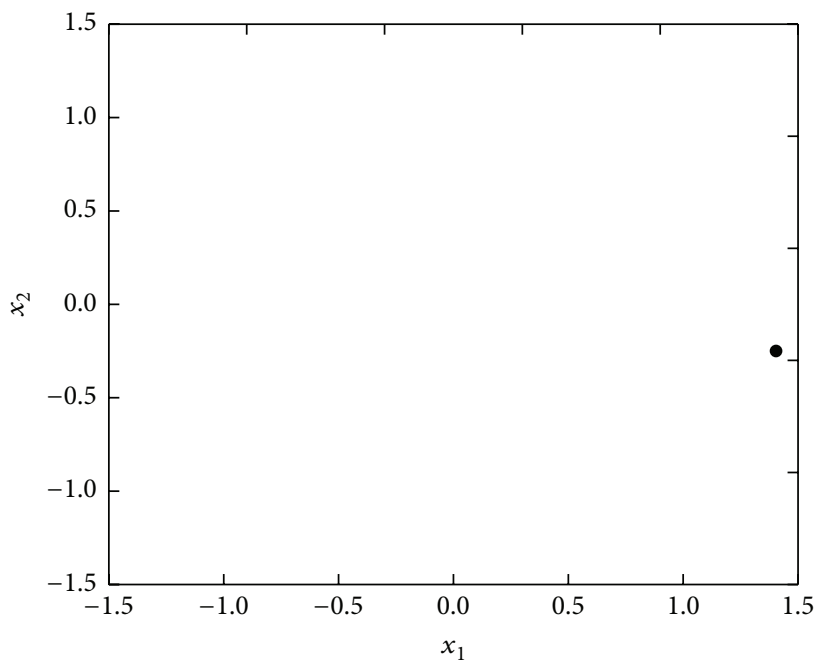

(f) Poincare section

Figure 4: Period responses of the system $\left(q_{3}=7.24\right)$. 


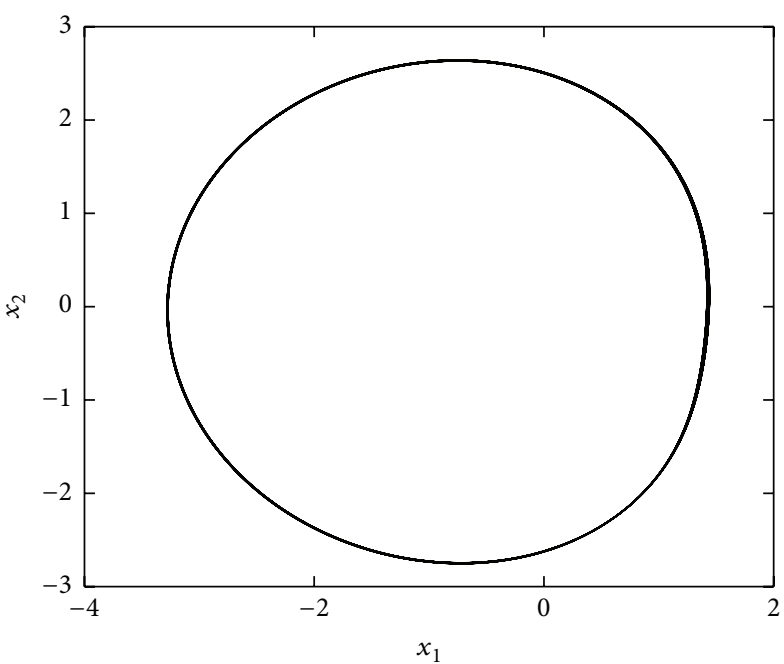

(a) Phase diagram of the axial modal

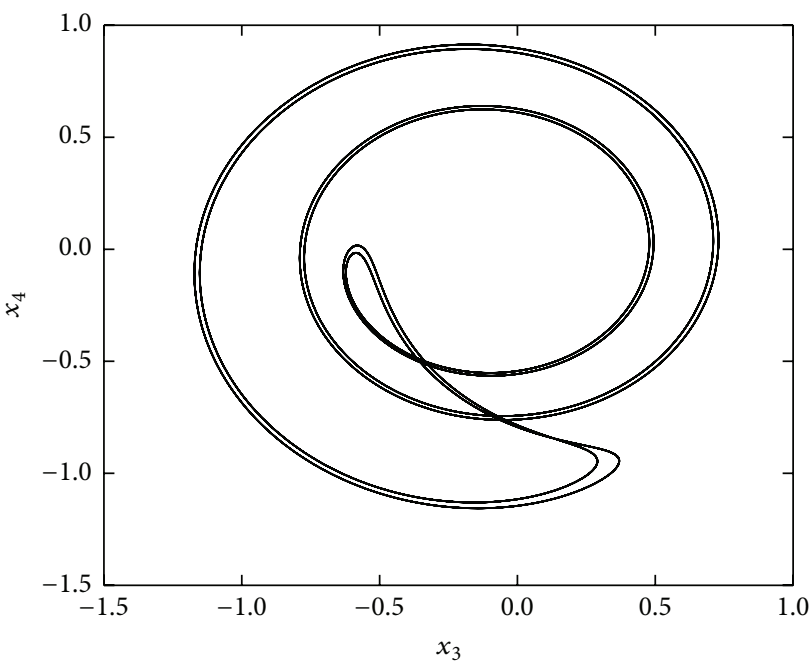

(c) Phase diagram of the torsional modal

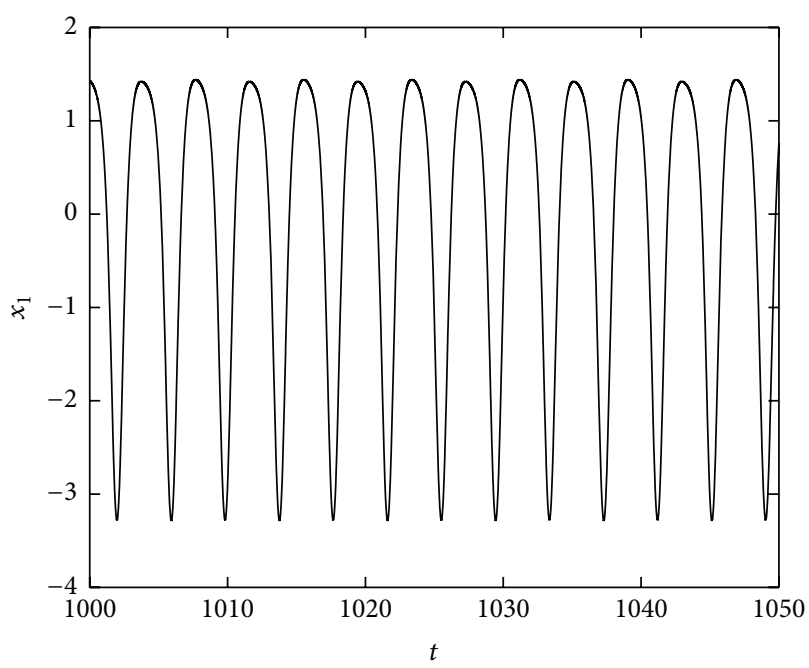

(b) Oscillogram of the axial modal

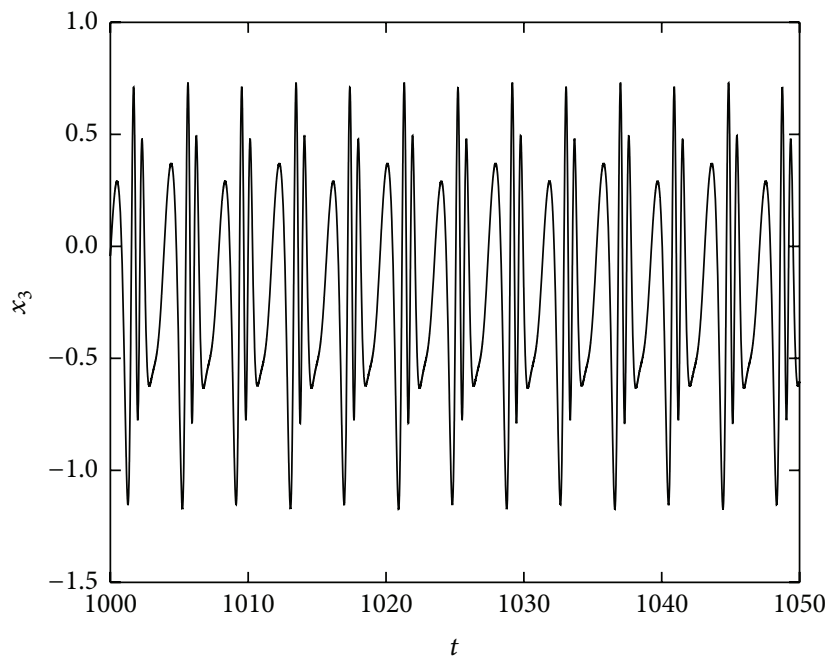

(d) Oscillogram of the torsional modal

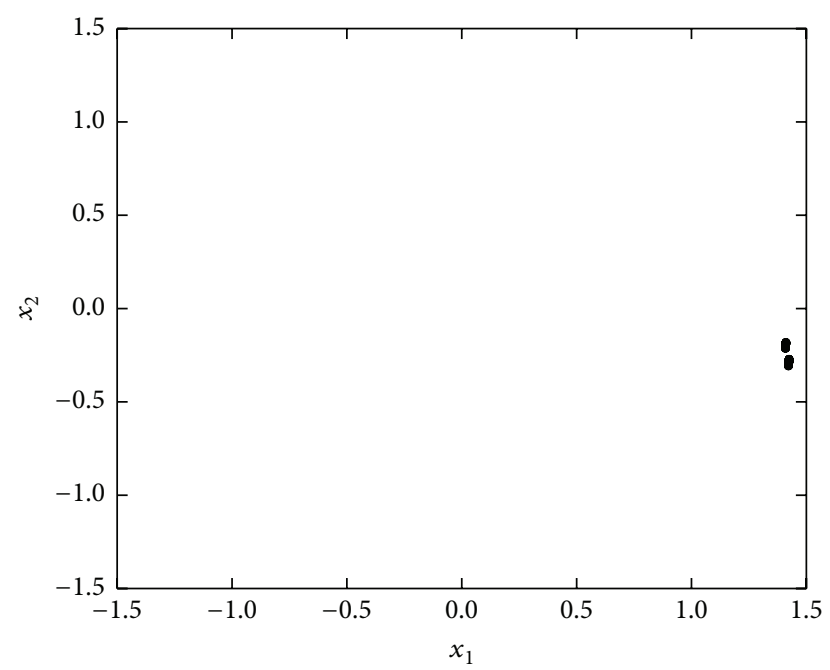

(f) Poincare section

(e) Three-dimensional phase diagram

Figure 5: Period responses of the system $\left(q_{3}=7.26\right)$. 


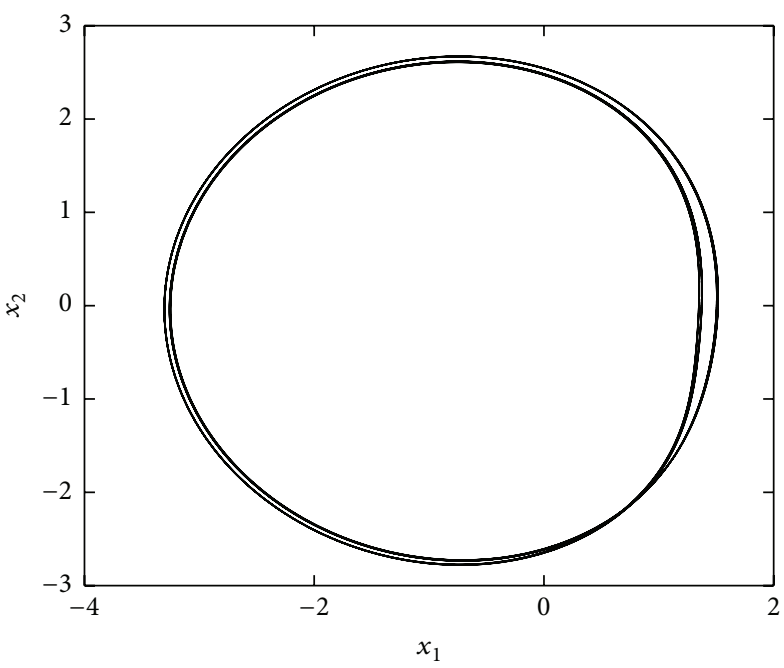

(a) Phase diagram of the axial modal

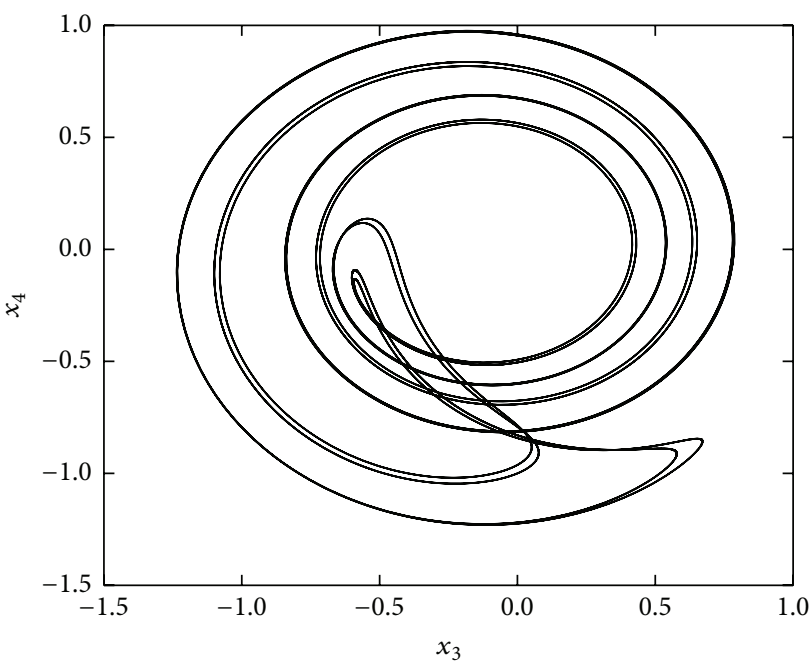

(c) Phase diagram of the torsional modal

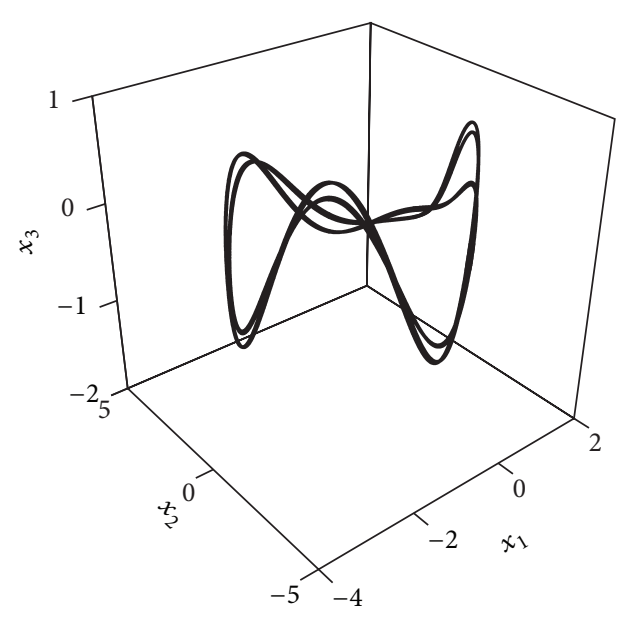

(e) Three-dimensional phase diagram

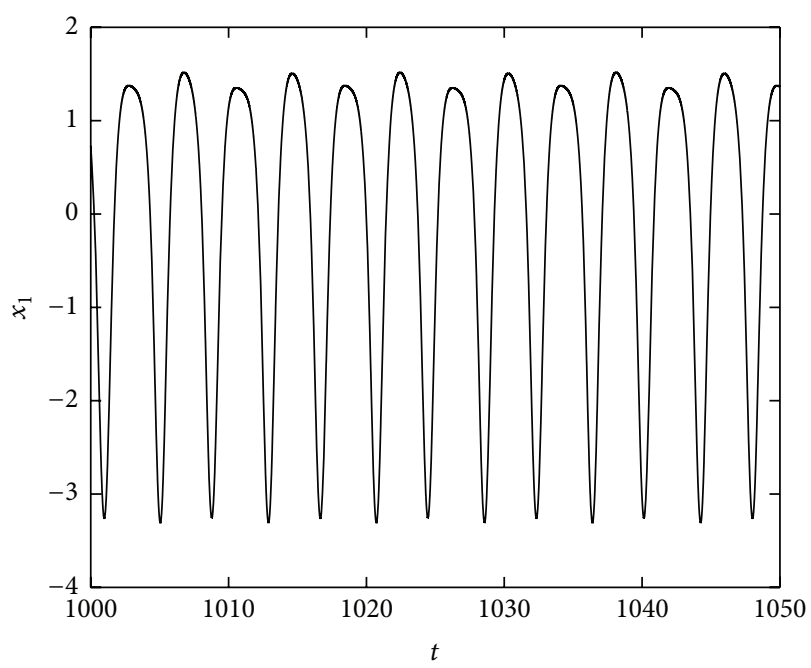

(b) Oscillogram of the axial modal

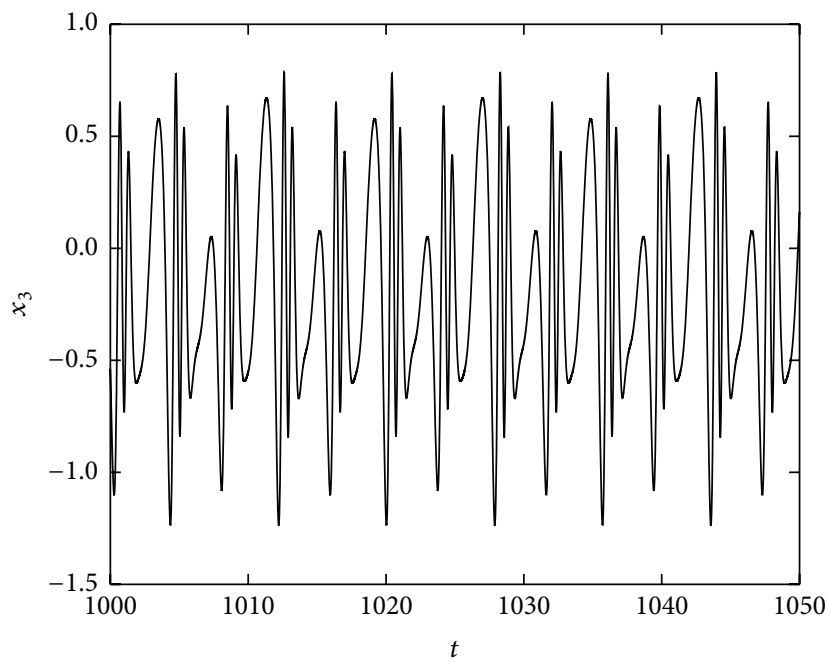

(d) Oscillogram of the torsional modal

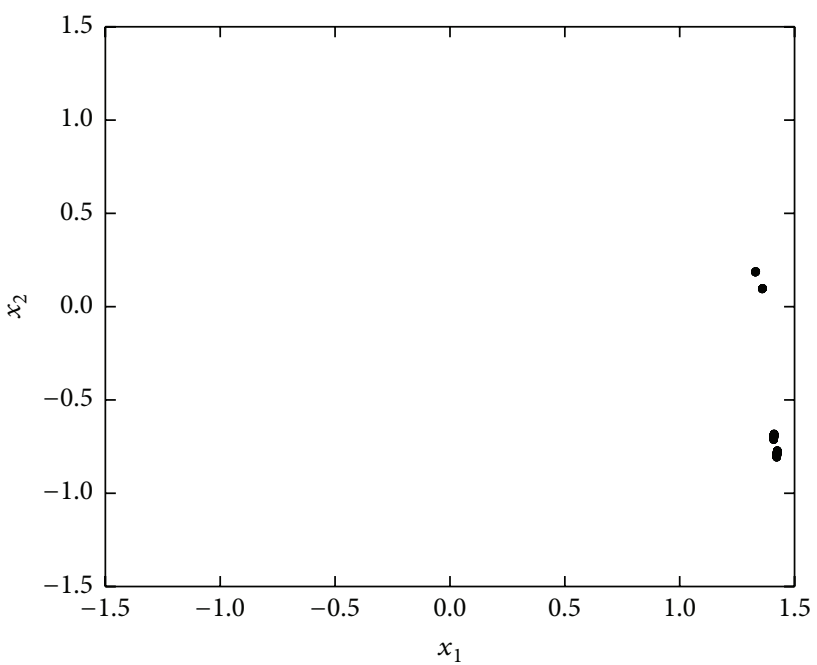

(f) Poincare section

FIGURE 6: Period responses of the system $\left(q_{3}=7.5\right)$. 


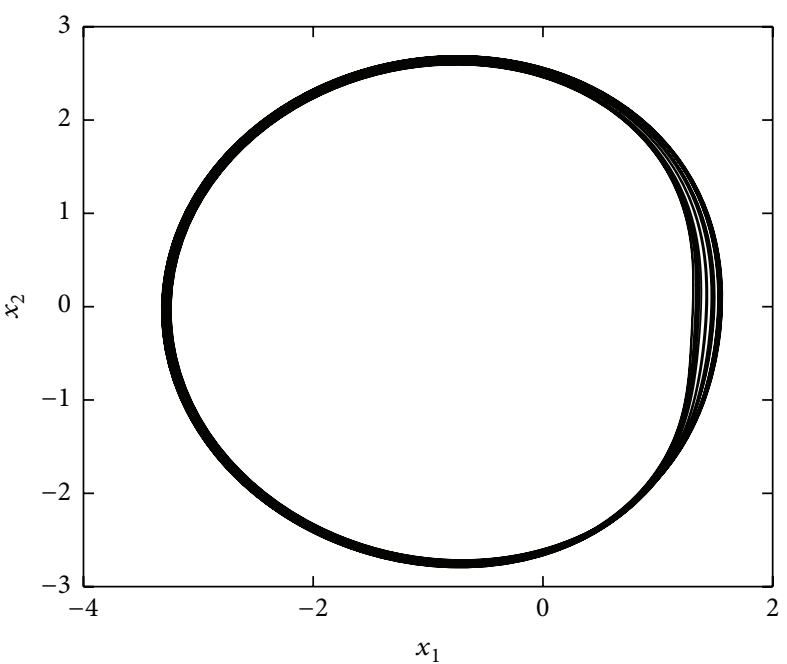

(a) Phase diagram of the axial modal

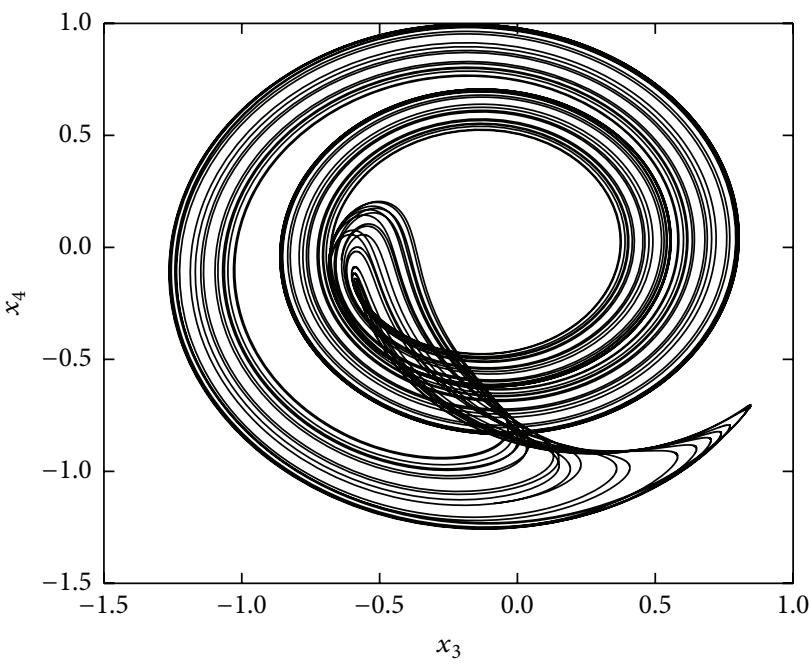

(c) Phase diagram of the torsional modal

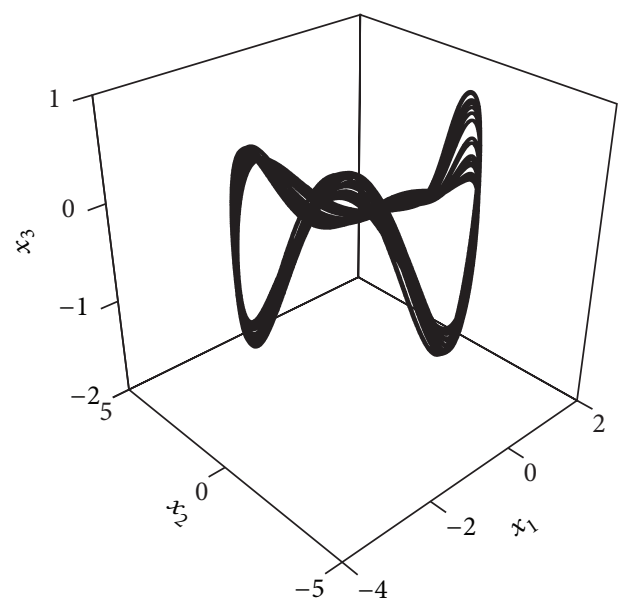

(e) Three-dimensional phase diagram

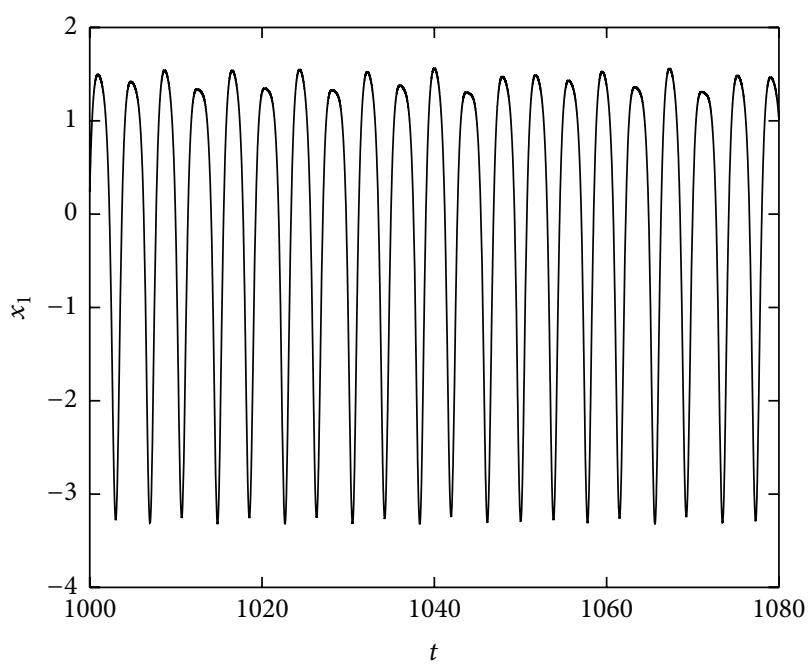

(b) Oscillogram of the axial modal

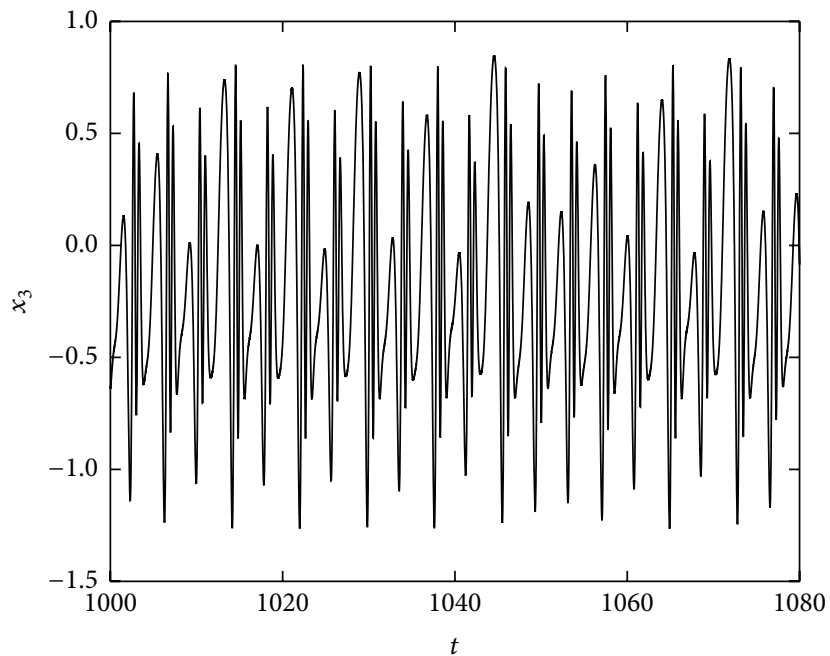

(d) Oscillogram of the torsional modal

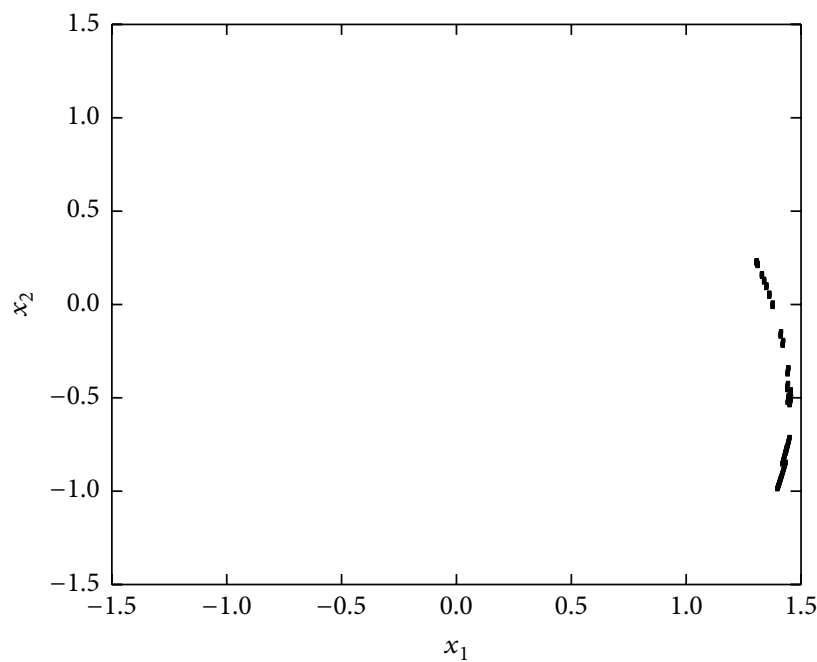

(f) Poincare section

Figure 7: The almost-periodic responses of the system $\left(q_{3}=7.68\right)$. 


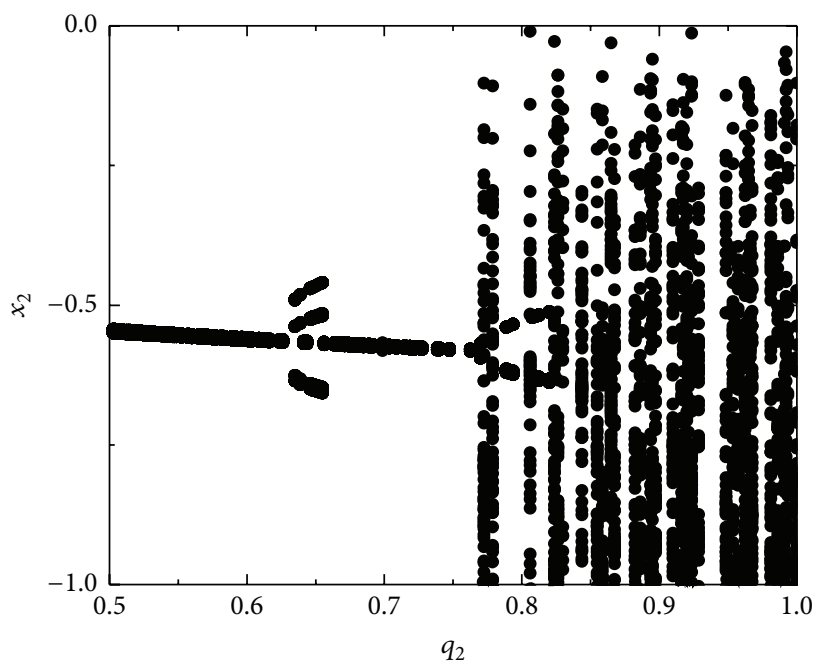

(a) Bifurcation diagram of the axial modal

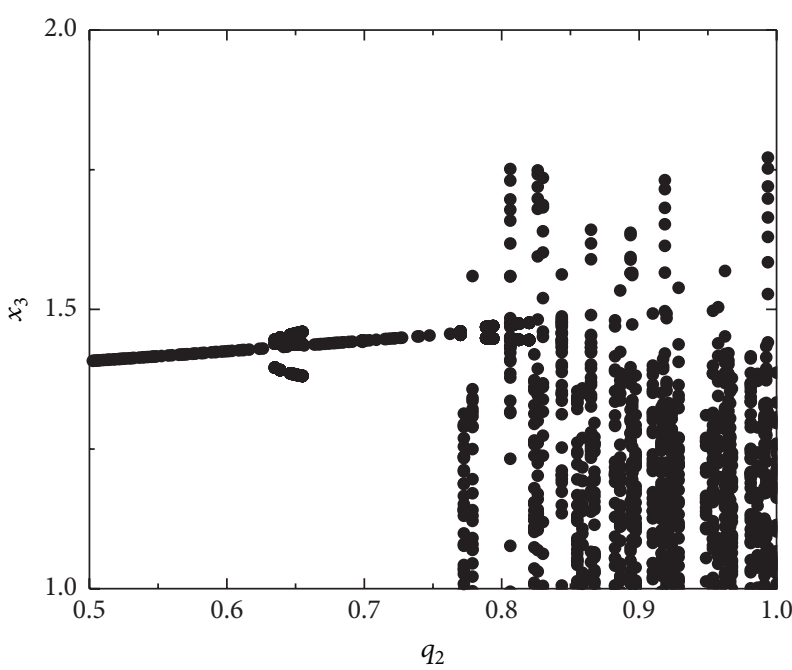

(b) Bifurcation diagram of the torsional modal

FIGURE 8: Bifurcation of the resonance frequency-multiplier.

a constant WOB, in the case of a lower-rotation speed and lower rock hardness, high drill efficiency can be attained by properly increasing the WOB. In the case of high-rotation speed, the coupling vibration is sensitive to the axial stress, so the proper WOB should be adopted to avoid the coupling vibration of the drill string based on geological parameters.

\section{Conclusions}

In this paper, we modeled and analyzed drill-string vibrations by focusing on the coupled axial/torsional vibrations by means of nonlinear dynamics and qualitative analysis, aiming at revealing the key, effective factors influencing the coupled vibrations. Here, the drill string was described as a simplified, equivalent, flexible shell under axial rotation, in which the excitation loads and boundary conditions of the drill string were simplified. After dimensionless processing, we built the dynamics motion equation and the average equation.

We found that the low-frequency amplitude expression of the torsional excitation and the high-frequency amplitude expression of the axial excitation in the average equation are the factors that determine the coupling vibration. Based on this procedure, numerical simulations were carried out with adaptive steps using the Runge-Kutta-Fehlberg method to discover the response of the system vibrations. Further, we found that a change in the torsional or the axial excitation affects both the torsional and the axial vibration simultaneously and that it is similar qualitatively and synchronous in form.

The results of the simulation analysis show that when the drill string is in a lower-speed rotation zone, the torsional excitation mainly contributes to the coupling vibration, increasing the torsional stress of the drill string that more easily leads to the coupling vibration. When in a higher-speed rotating zone, the axial excitation mainly contributes to the coupling vibration; so, in a particular interval, it is more likely to cause the coupling vibration of the drill string.

\section{Appendix}

Consider

$$
\begin{aligned}
& a_{1}=-\frac{1}{2 L \rho \pi}, \\
& a_{2}=\frac{1}{\rho}\left(\frac{1}{12} \frac{h^{3} E_{2}}{R^{3}}-\frac{h E_{2}}{R}-\frac{1}{4} \frac{\pi^{2} R h E_{1}}{L^{2}}\right), \\
& a_{3}=\frac{1}{\rho}\left(\frac{8}{45} \frac{h^{3} E_{2}}{L R^{2}}-\frac{32}{15} \frac{h E_{2}}{L}-\frac{32}{15} \frac{h \kappa E_{1}}{L}\right) \text {, } \\
& a_{4}=\frac{1}{\rho}\left(\frac{1}{4} \frac{\pi^{2} h^{3} \kappa E_{1}}{L^{3} R^{3}}-\frac{13}{16} \frac{\pi^{2} h \kappa E_{1}}{L^{2} R}-\frac{1}{4} \frac{h E_{2}}{R^{3}}\right. \\
& \left.-\frac{1}{16} \frac{\pi^{4} R h E_{1}}{L^{4}}\right) \\
& a_{5}=\frac{1}{\rho}\left(\frac{1}{384} \frac{\pi^{2} h^{3} E_{2}}{L^{2} R^{3}}-\frac{9}{512} \frac{\pi^{4} R h E_{1}}{L^{4}}-\frac{3}{32} \frac{h^{3} E_{2}}{R^{5}}\right. \\
& \left.-\frac{9}{32} \frac{h E_{2}}{R^{3}}-\frac{1}{32} \frac{\pi^{2} h E_{1}}{L^{2} R}-\frac{1}{64} \frac{\pi^{2} h \kappa E_{1}}{L^{2} R}\right), \\
& a_{6}=\frac{13 h \kappa E_{1}}{15 \rho L}, \\
& a_{7}=\frac{1}{\rho}\left(\frac{1}{4} \frac{\pi^{2} h^{3} \kappa E_{1}}{L^{2} R^{3}}+\frac{13}{16} \frac{\pi^{2} h \kappa E_{1}}{L^{2} R}-\frac{1}{4} \frac{h E_{1}}{R^{3}}\right. \\
& +\frac{1}{16} \frac{\pi^{4} R h E_{1}}{L^{4}}+\frac{3}{4} \frac{h E_{1}}{L^{3}}+\frac{1}{24} \frac{\pi^{2} h^{3} E_{2}}{L^{2} R^{3}} \\
& \left.+\frac{9}{2} \frac{\pi^{4} R h E_{1}}{L^{4}}\right) \\
& a_{8}=\frac{1}{\rho}\left(\frac{1}{2} \frac{\pi^{2} h E_{2}}{L^{2} R}+\frac{3}{2} \frac{\pi^{4} h^{3} E_{1}}{L^{4} R}+\frac{\pi^{2} h \kappa E_{1}}{L^{2} R}+\frac{3}{4} \frac{h E_{1}}{L^{3}}\right.
\end{aligned}
$$




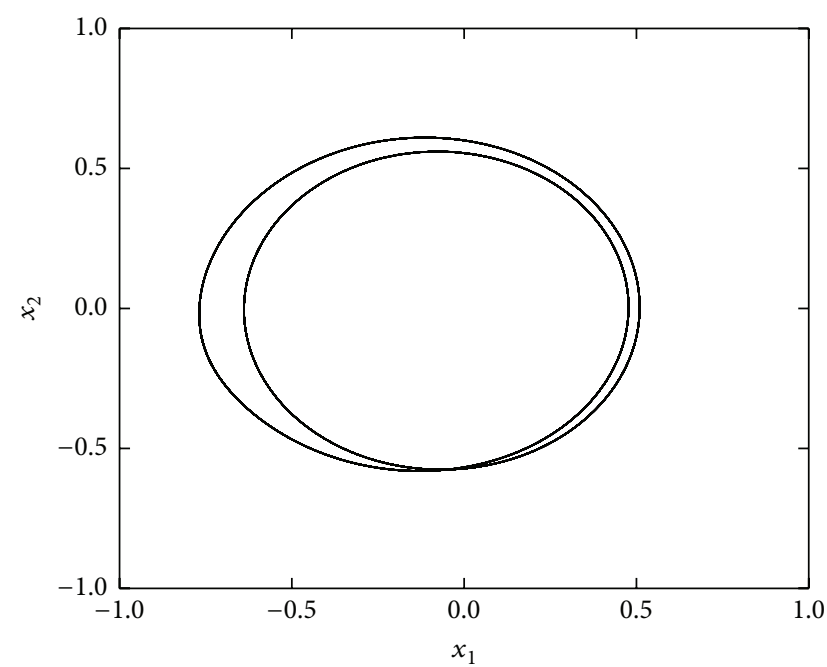

(a) Phase diagram of the axial modal

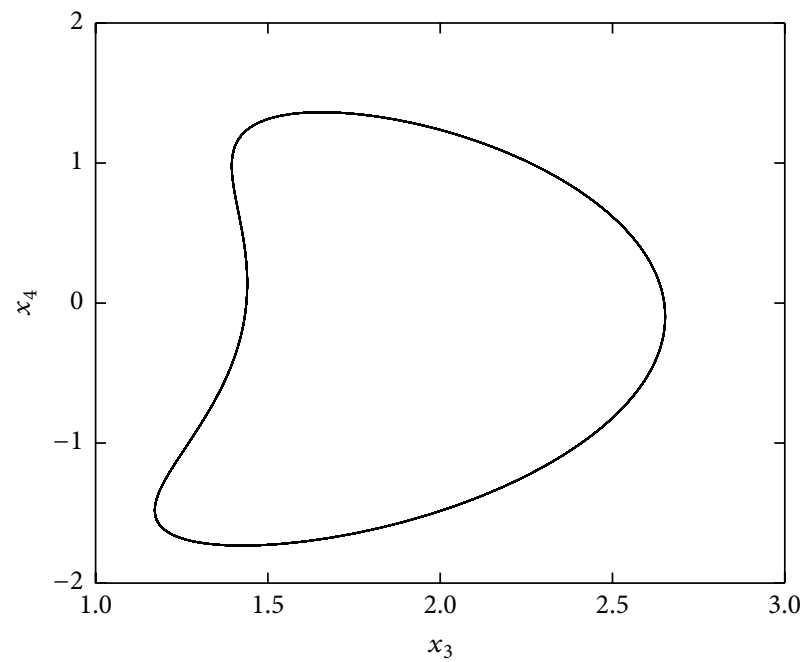

(c) Phase diagram of the torsional modal

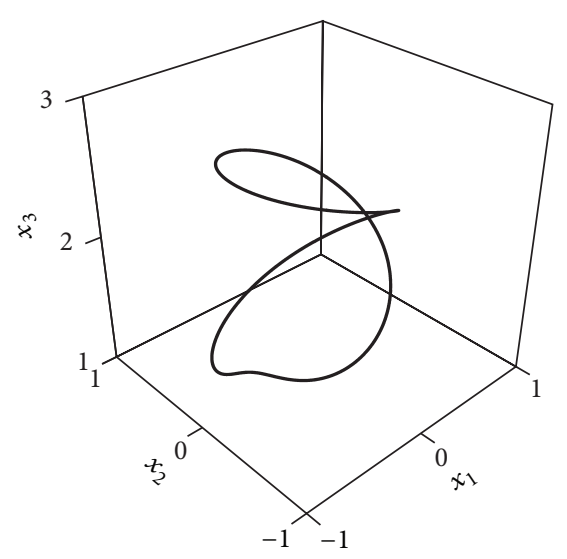

(e) Three-dimensional phase diagram

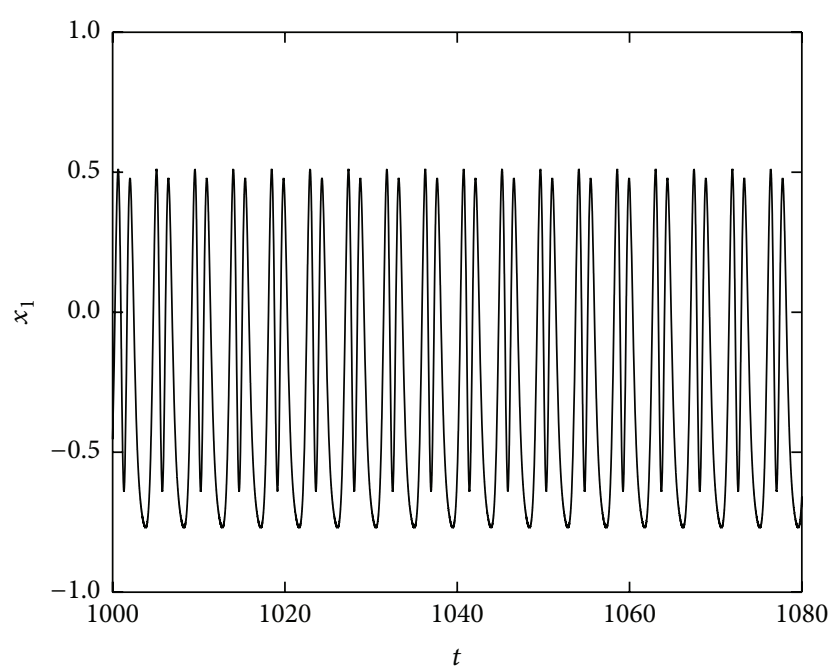

(b) Oscillogram of the axial modal

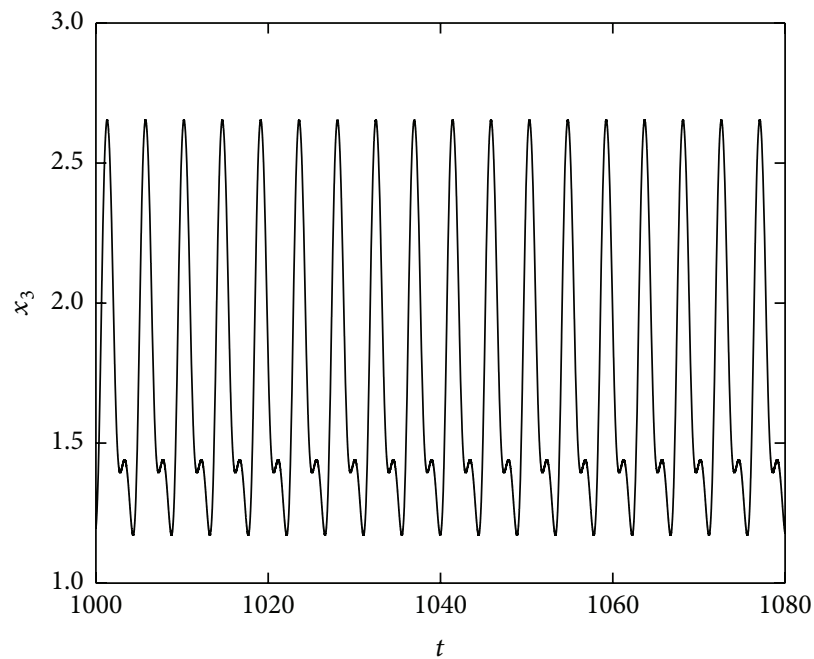

(d) Oscillogram of the torsional modal

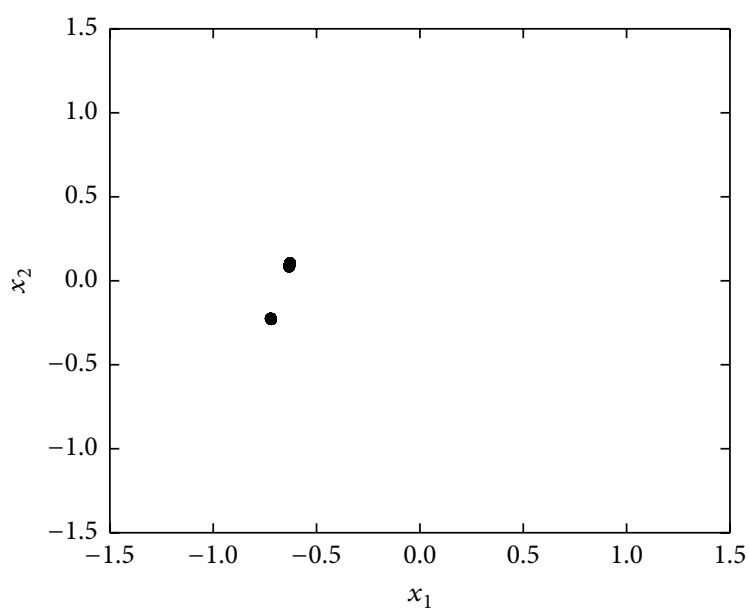

(f) Poincare section

Figure 9: Period responses of the system $\left(q_{2}=0.5025\right)$. 


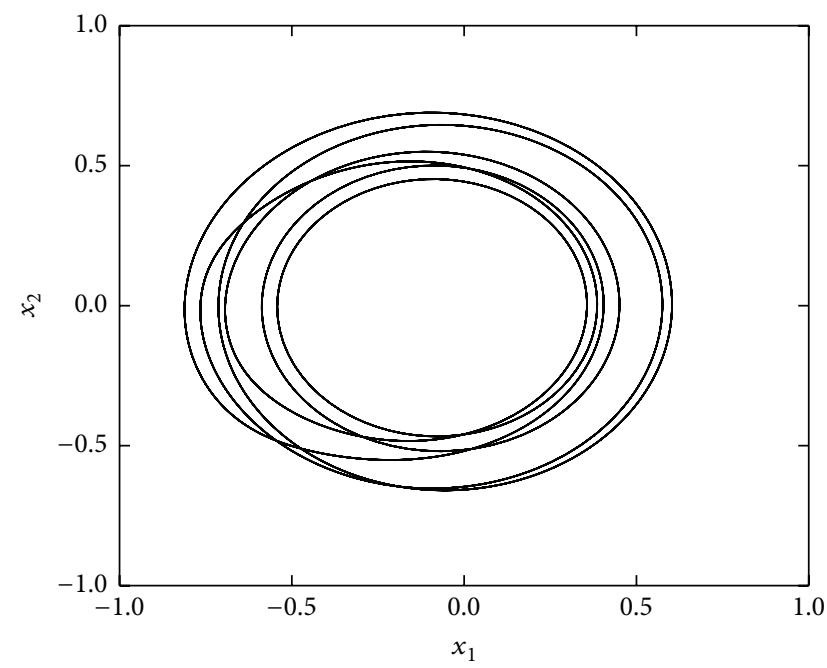

(a) Phase diagram of the axial modal

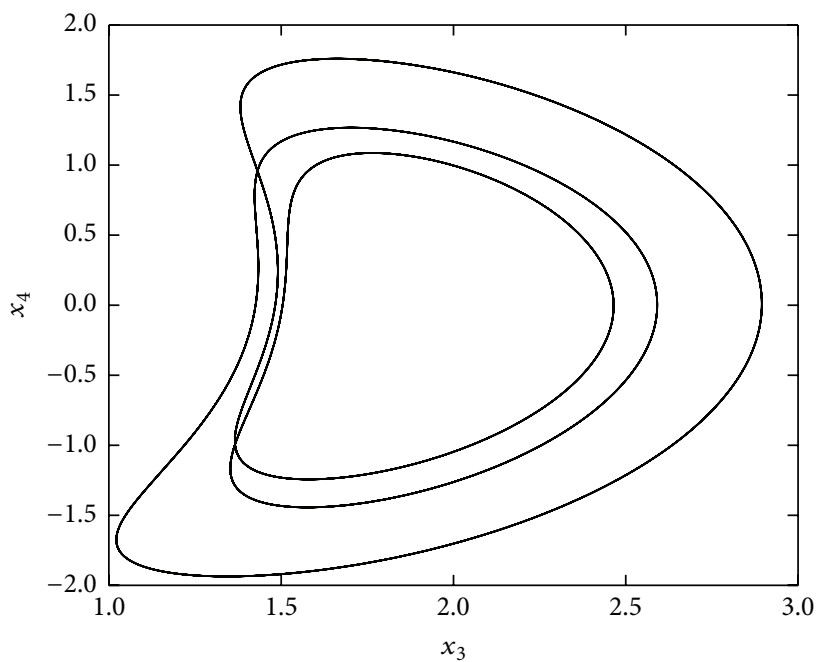

(c) Phase diagram of the torsional modal

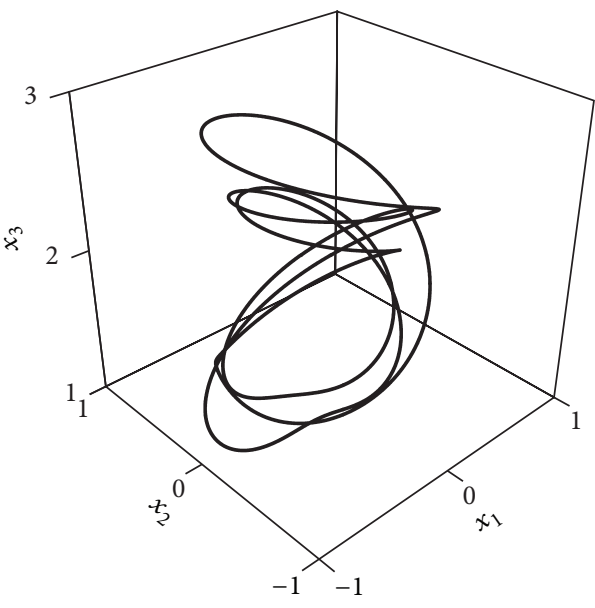

(e) Three-dimensional phase diagram

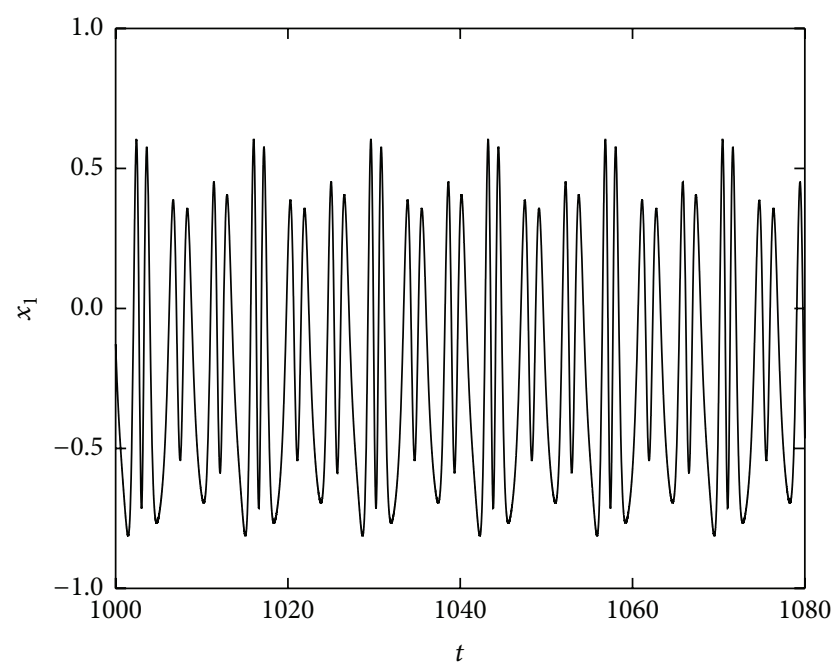

(b) Oscillogram of the axial modal

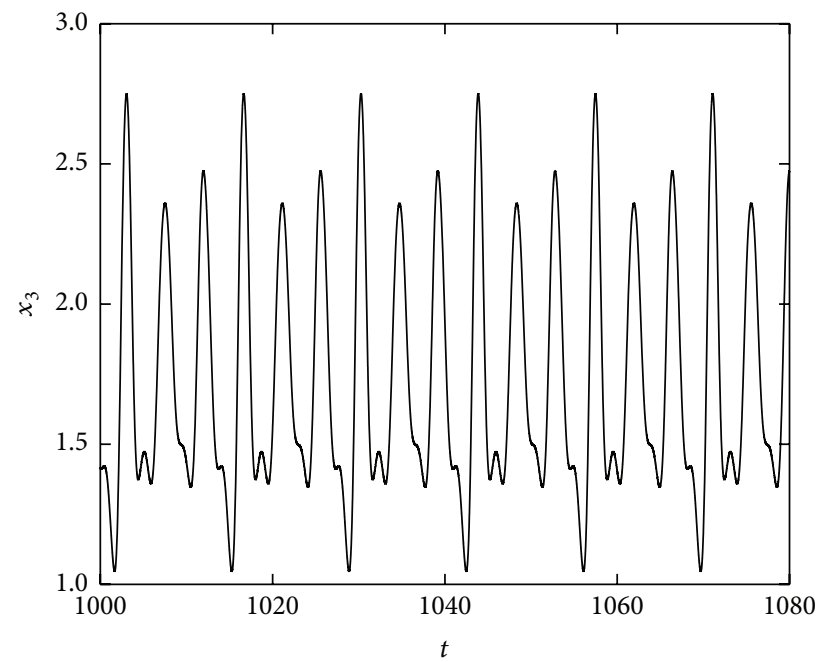

(d) Oscillogram of the torsional modal

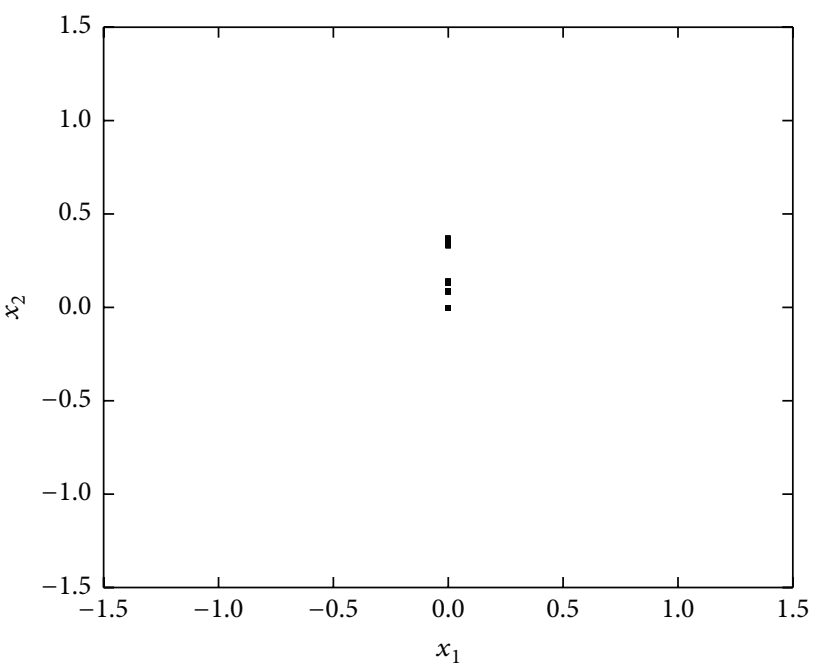

(f) Poincare section

FIgURe 10: Period responses of the system $\left(q_{2}=0.635\right)$. 


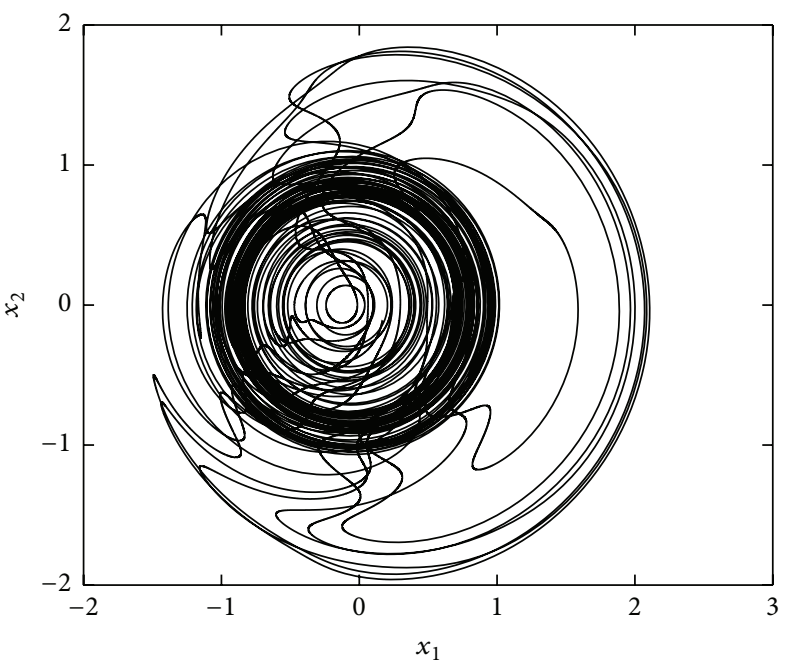

(a) Phase diagram of the axial modal

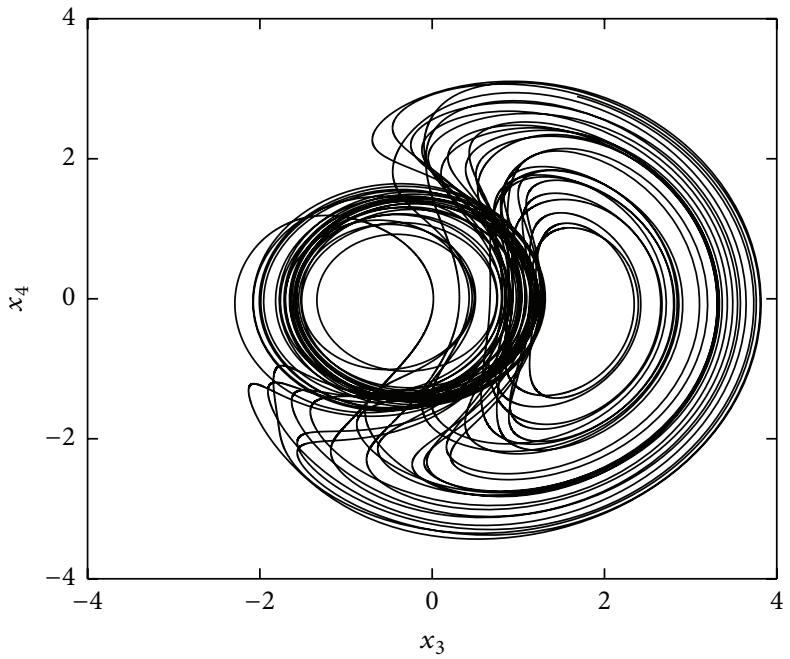

(c) Phase diagram of the torsional modal

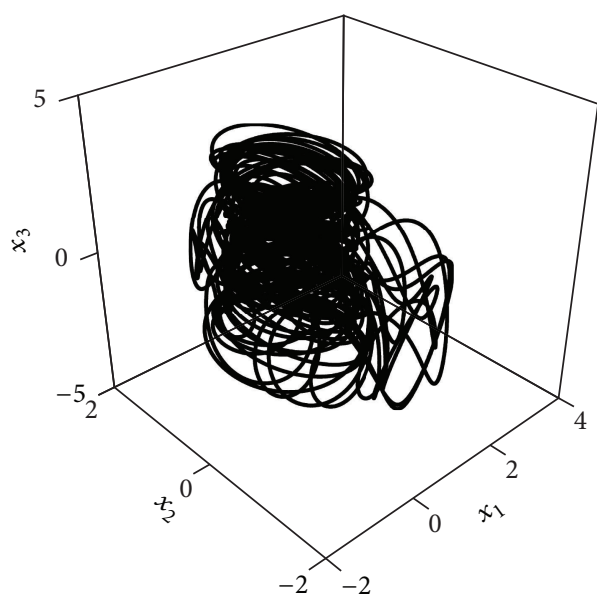

(e) Three-dimensional phase diagram

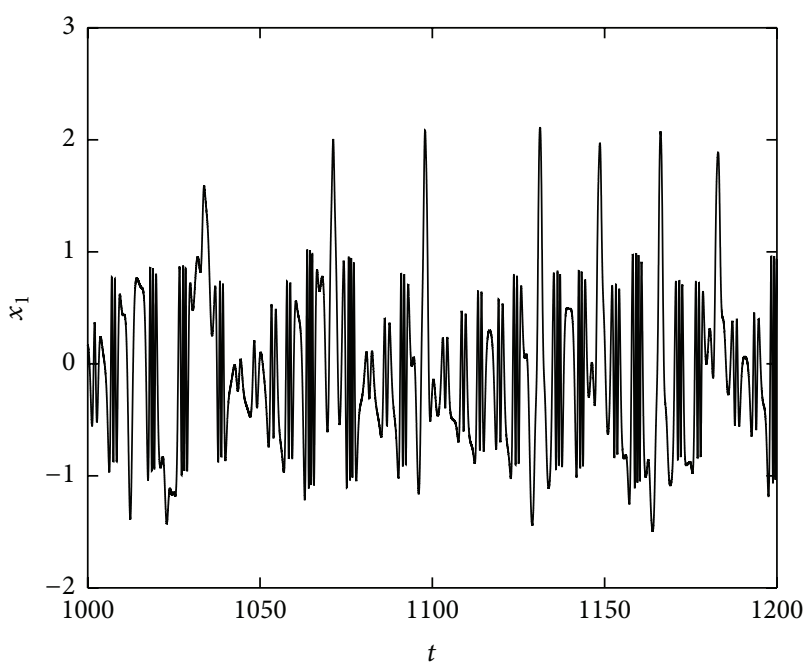

(b) Oscillogram of the axial modal

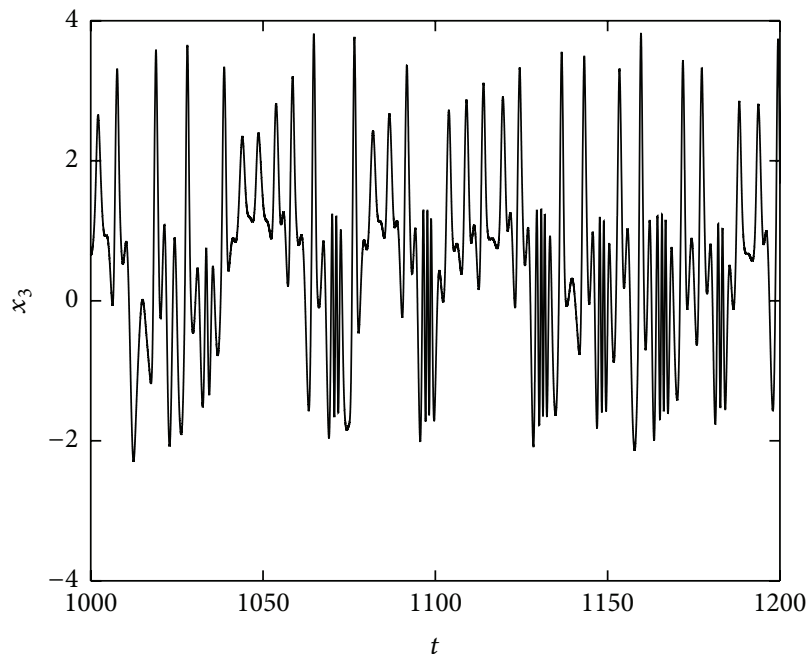

(d) Oscillogram of the torsional modal

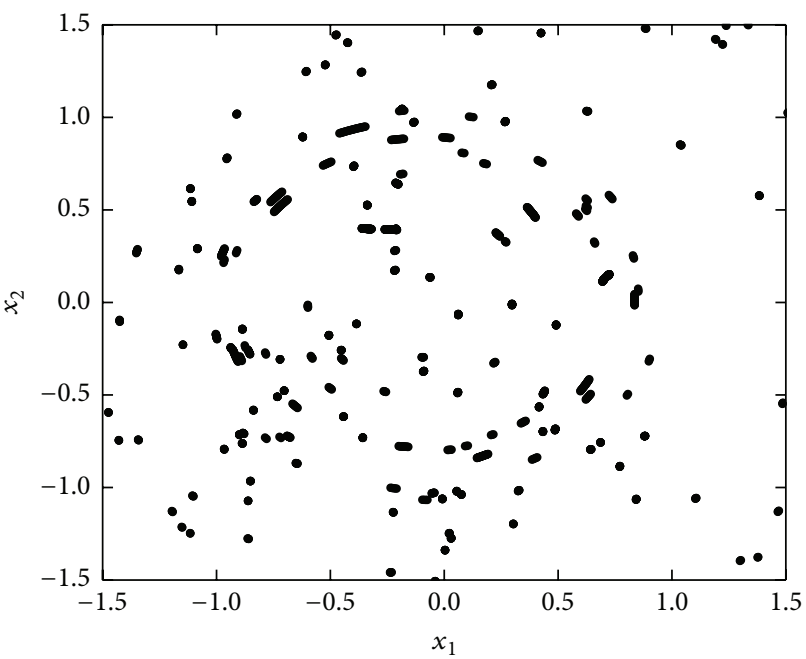

(f) Poincare section

FIGURE 11: Period responses of the system $\left(q_{2}=0.7725\right)$. 


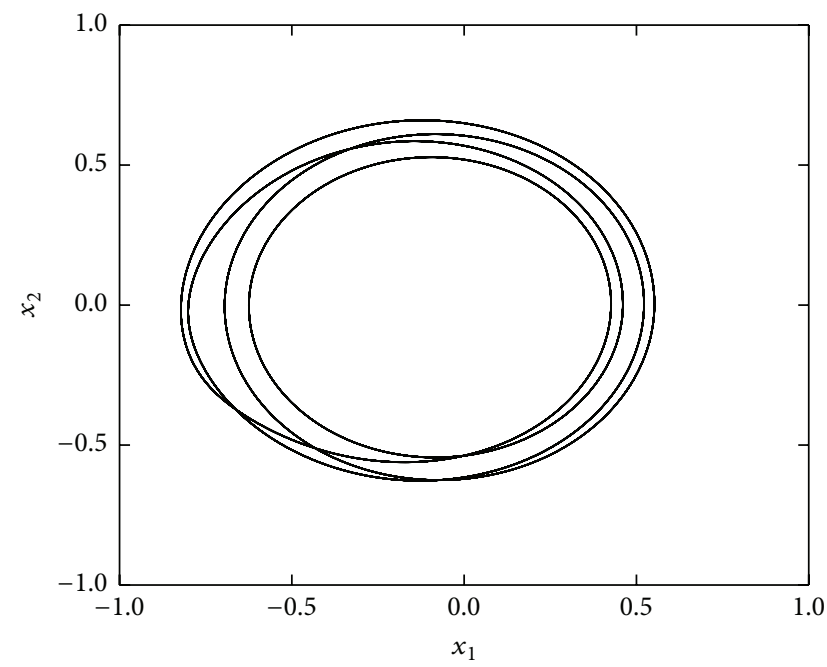

(a) Phase diagram of the axial modal

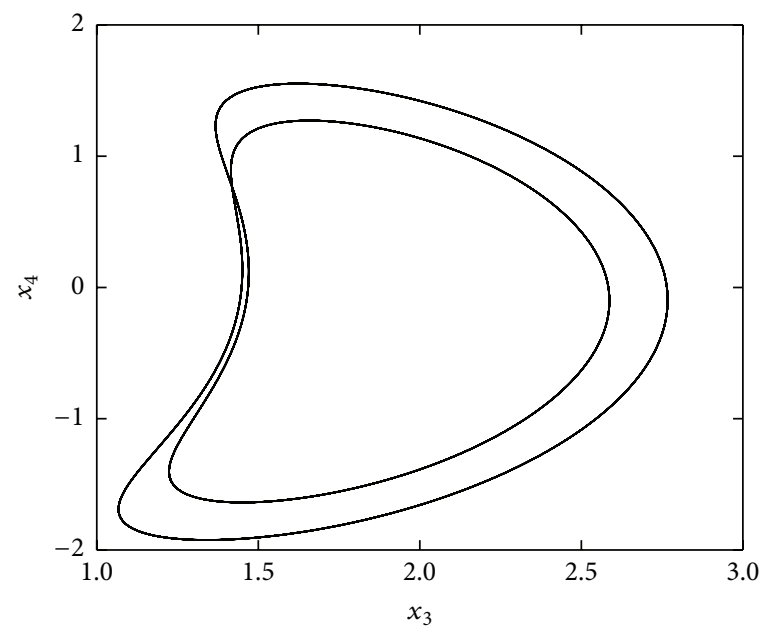

(c) Phase diagram of the torsional modal

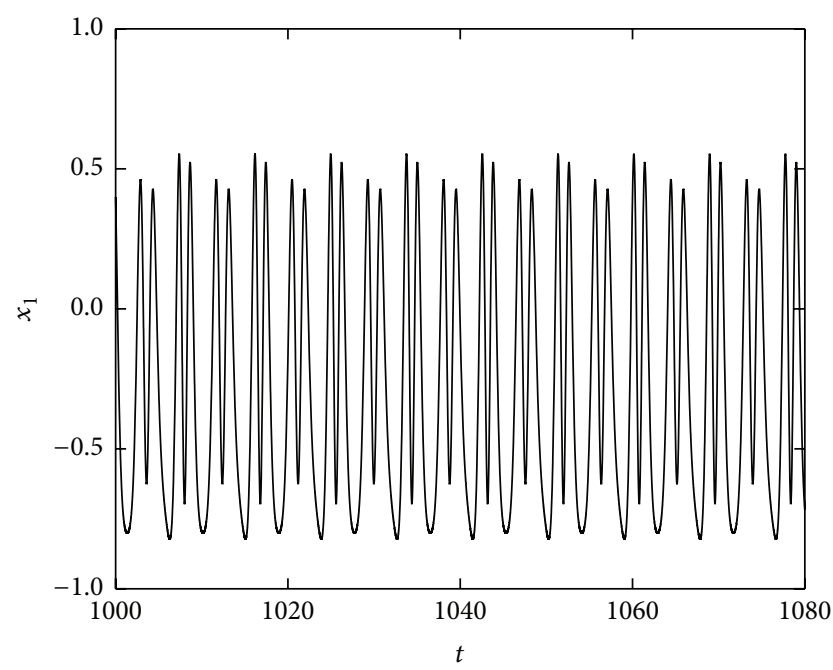

(b) Oscillogram of the axial modal

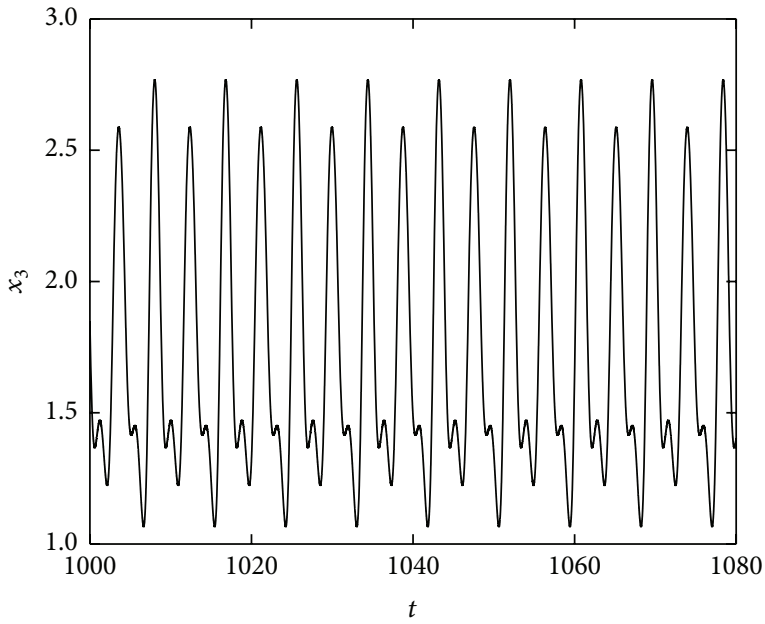

(d) Oscillogram of the torsional modal

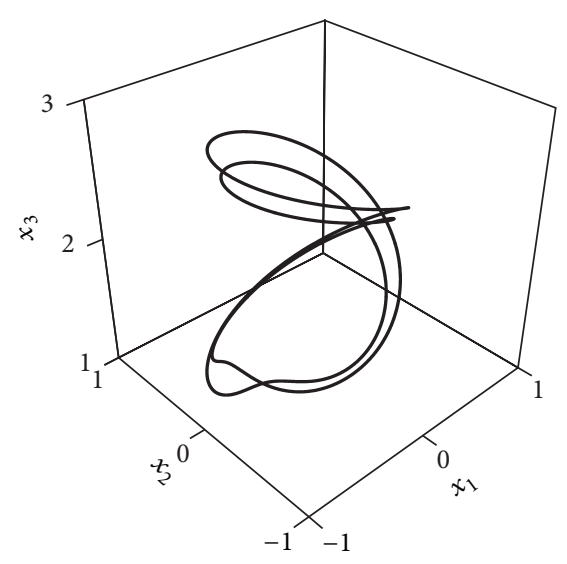

(e) Three-dimensional phase diagram

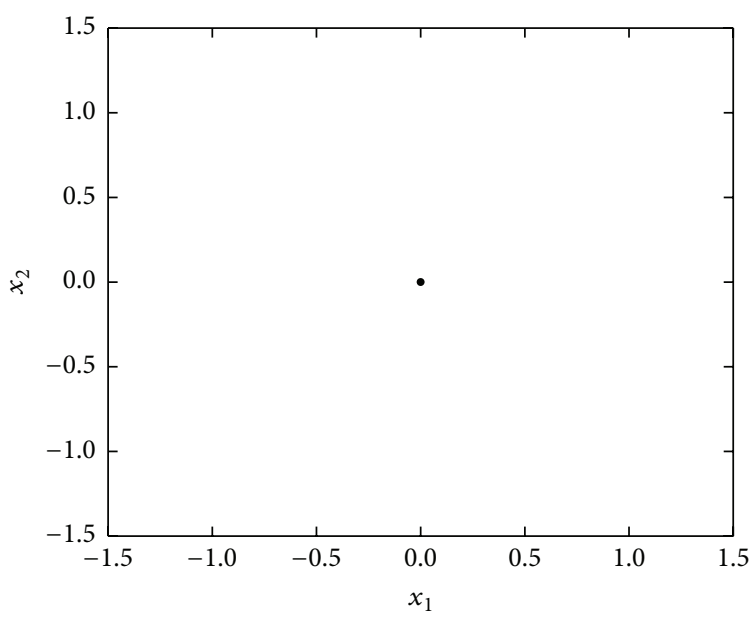

(f) Poincare section

Figure 12: Period-doubled responses of the system $\left(q_{2}=0.79\right)$. 


$$
\begin{aligned}
+ & \left.\frac{1}{24} \frac{\pi^{2} h^{3} E_{2}}{L^{2} R^{3}}+\frac{9}{2} \frac{\pi^{4} R h E_{1}}{L^{4}}\right), \\
a_{9} & =\frac{C_{1}}{2 \pi R \sqrt{\rho E}}, \\
a_{10} & =\frac{\pi^{2} h^{3} E_{1} \kappa}{4 L^{2} \rho R^{2}}-\frac{h E_{1}}{4 \rho R^{2}}-\frac{\pi^{4} h R E_{1}}{16 L^{4} \rho}-\frac{\pi^{2} h E_{1} \kappa}{16 L^{2} \rho R}, \\
a_{11} & =-\frac{9 \pi^{4} h R E_{1}}{512 L^{4} \rho}-\frac{3 h^{3} E_{1}}{32 \rho R^{5}}-\frac{\pi^{2} h E_{2}}{32 L^{2} \rho R}-\frac{\pi^{2} h^{3} E_{2}}{384 L^{2} \rho R^{3}} \\
& \frac{9 h E_{1}}{32 \rho R^{3}}-\frac{\pi^{2} h E_{1} \kappa}{64 L^{2} \rho R}, \\
a_{12} & =\frac{C_{2}}{2 \pi R \sqrt{\rho E}}, \\
a_{13} & =-\frac{4 \pi^{2} R h E_{2}}{L^{2} \rho}-\frac{h E_{1}}{R \rho}-\frac{\pi^{2} h^{3} E_{2}}{3 L^{2} \rho R}, \\
a_{15} & =-\frac{\pi^{2} h^{3} E_{2}}{24 L^{2} \rho R^{3}}-\frac{\pi^{2} h E_{2}}{2 L^{2} \rho R}-\frac{9 \pi^{4} h E_{1} \kappa}{2 L^{4} \rho}-\frac{3 h E_{1}}{4 \rho E^{3}} \\
a_{14}= & \frac{\pi^{2} h^{3} E_{1} \kappa}{4 L^{2} \rho R^{3}}-\frac{h E_{1}}{4 \rho R^{3}}-\frac{\pi^{4} h R E_{1}}{16 L^{4} \rho}-\frac{13 \pi^{2} h E_{1} \kappa}{16 L^{2} \rho R},
\end{aligned}
$$

\section{Conflict of Interests}

The authors declare that there is no conflict of interests regarding the publication of this paper.

\section{Acknowledgments}

The authors would like to acknowledge financial support by Natural Science Foundation of China, Project 11372071, and Postdoctoral Fund of China, Project 2013M541339.

\section{References}

[1] P. D. Spanos, A. M. Chevallier, N. Politis, and B. Payne, "Oil well drilling: a vibration perspective," The Shock and Vibration Digest, vol. 35, pp. 81-99, 2013.

[2] W. D. Aldred and M. C. Sheppard, "Drillstring vibrations: a new generation mechanism and control strategies," in Proceedings of the SPE Annual Technical Conference and Exhibition, SPE24582-MS, pp. 353-363, Washington, DC, USA, October 1992.

[3] T. V. Aarrestand, H. A. Tonnesen, and A. Kyllingstad, "Drillstring vibrations: theory and experiments on full-scale research drilling rig," in Proceedings of the IADC/SPE Drilling Conference, SPE Paper No. 14760, pp. 311-321, Dallas, Tex, USA, 1986.

[4] J. D. Jansen, "Non-linear rotor dynamics as applied to oilwell drillstring vibrations," Journal of Sound and Vibration, vol. 147, no. 1, pp. 115-135, 1991.
[5] A. S. Yigit and A. P. Christoforou, "Coupled axial and transverse vibrations of oilwell drillstrings," Journal of Sound and Vibration, vol. 195, no. 4, pp. 617-627, 1996.

[6] A. S. Yigit and A. P. Christoforou, "Coupled torsional and bending vibration of drill-strings subject to impact with friction," Journal of Sound and Vibration, vol. 215, no. 1, pp. 167-181, 1998.

[7] K. Z. Khan, Longitudinal and torsional vibration of drillstrings [M.S. thesis], Massachusetts Institute of Technology, Cambridge, Mass, USA, 1986.

[8] R. J. Shyu, Bending of rotating drill-strings [Ph.D. thesis], Massachusetts Institute of Technology, 1989.

[9] A. P. Christoforou and A. S. Yigit, "Fully coupled vibrations of actively controlled drillstrings," Journal of Sound and Vibration, vol. 267, no. 5, pp. 1029-1045, 2003.

[10] M. A. Trindade, C. Wolter, and R. Sampaio, "Karhunen-Loève decomposition of coupled axial/bending vibrations of beams subject to impacts," Journal of Sound and Vibration, vol. 279, no. 3-5, pp. 1015-1036, 2005.

[11] R. Sampaio, M. T. Piovan, and G. Venero Lozano, "Coupled axial/torsional vibrations of drill-strings by means of non-linear model," Mechanics Research Communications, vol. 34, no. 5-6, pp. 497-502, 2007.

[12] H. Hakimi and S. Moradi, "Drillstring vibration analysis using differential quadrature method," Journal of Petroleum Science and Engineering, vol. 70, no. 3-4, pp. 235-242, 2010.

[13] F. S. Ren, S. Chen, and Z. G. Yao, "Dynamics analysis and vibration suppression of a flexible rotation beam," Applied Mechanics and Materials, vol. 214, pp. 165-172, 2012.

[14] F.-S. Ren and Z.-G. Yao, "Study on nonlinear dynamics and bifurcations in rotating compressive-drill string," Engineering Mechanics, vol. 30, no. 10, pp. 251-256, 2013.

[15] Z.-F. Li, Y.-G. Zhang, X.-T. Hou, W.-D. Liu, and G.-Q. Xu, "Analysis of longitudinal and torsion vibration of drill-strings," Engineering Mechanics, vol. 21, no. 6, pp. 203-210, 2004 (Chinese).

[16] G. J. Sheu and S. M. Yang, "Dynamic analysis of a spinning Rayleigh beam," International Journal of Mechanical Sciences, vol. 47, no. 2, pp. 157-169, 2005.

[17] X. Zhou, X. Qichong, D. Hu et al., "The nonlinear dynamics analysis of bottom drillstring of air drilling," Journal of Chongqing University of Science and Technology, vol. 4, pp. 119121, 2013 (Chinese).

[18] Y.-J. Jia, P. Jiang, X.-H. Zhu, and Y.-F. Zhang, "Nonlinear buckling simulation of drillstring system during pilot hole drilling in horizontal directional drilling," Journal of System Simulation, vol. 25, no. 4, pp. 821-825, 2013 (Chinese).

[19] W.-S. Xiao, Z.-Y. Liu, H.-Y. Wang, X.-F. Wang, L. Fu, and Y.C. Yin, "Tensional vibration analysis of drill-string by FSI," Oil Field Equipment, vol. 42, pp. 23-26, 2013 (Chinese).

[20] D. Shao, Z. Guan, X. Wen, and Y. Shi, "Experiment on lateral vibration characteristics of horizontal rotary drilling string," Journal of China University of Petroleum, vol. 37, pp. 100-105, 2013 (Chinese).

[21] W. Zhang, X. Zhu, Z. Zhou, and W. Ma, "Effect of rotational speeds mutation on the dynamic characteristics of the drillstring system in a vertical well," Journal of Petrochemical Universities, vol. 26, no. 2, pp. 47-51, 2013 (Chinese).

[22] Y. Tang, "Nonlinear vibrations of axially accelerating viscoelastic Timoshenko beams," Chinese Journal of Theoretical and Applied Mechanics, vol. 45, no. 6, pp. 965-973, 2013 (Chinese). 
[23] P. B. Gonçalves and Z. J. G. N. Del Prado, "Nonlinear oscillations and stability of parametrically excited cylindrical shells," Meccanica, vol. 37, no. 6, pp. 569-597, 2002.

[24] M. Strozzi and F. Pellicano, "Nonlinear vibrations of functionally graded cylindrical shells," Thin-Walled Structures, vol. 67, pp. 63-77, 2013.

[25] M. Amabili, Nonlinear Vibrations and Stability of Shells and Plates, Cambridge University Press, Cambridge, Cambridge, UK, 2008.

[26] A. W. Leissa, Vibrations of Shells, Government Printing Office, Washington, DC, USA, 1973.

[27] N. Yamaki, Elastic Stability of Circular Cylindrical Shells, NorthHolland, Amsterdam, The Netherlands, 1984.

[28] J. N. Reddy, Mechanics of Laminated Composite Plates and Shells, CRC Press, Boca Raton, Fla, USA, 2004.

[29] A. H. Nayfeh and D. T. Mook, Nonlinear Oscillations, WileyVCH Press, Weinheim, Germany, 2004.

[30] P. D. Spanos, A. K. Sengupta, R. A. Cunningham, and P. R. Paslay, "Modeling of roller cone bit lift-off dynamics in rotary drilling," Journal of Energy Resources Technology, vol. 117, no. 3, pp. 197-207, 1995. 


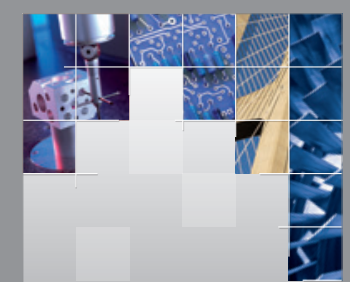

\section{Enfincering}
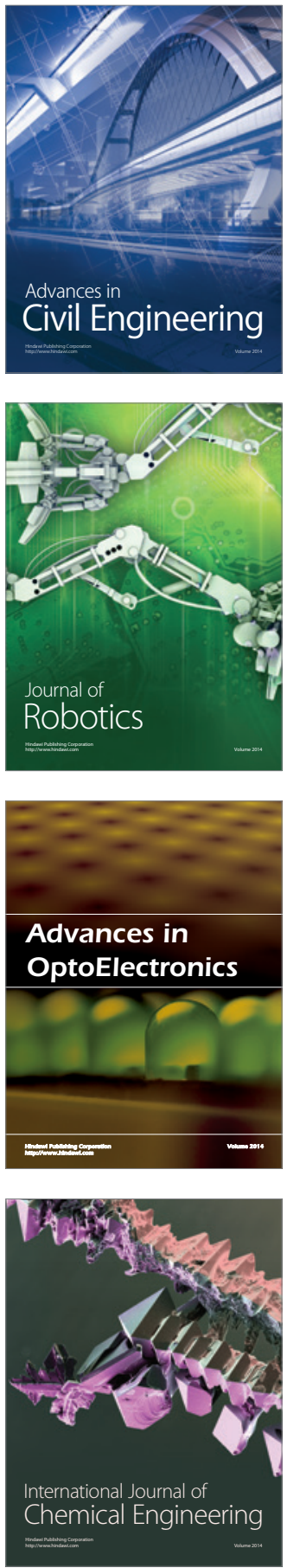

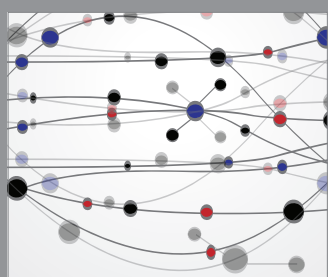

The Scientific World Journal

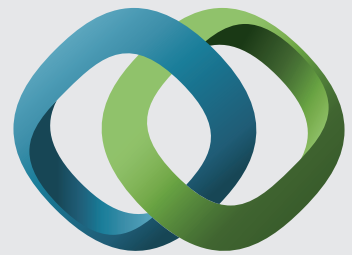

\section{Hindawi}

Submit your manuscripts at

http://www.hindawi.com
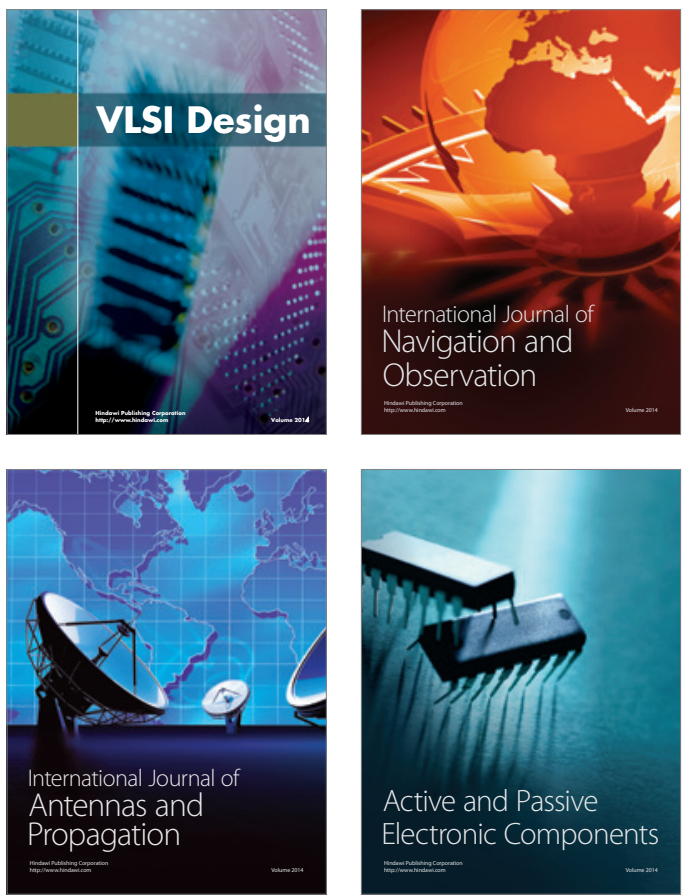
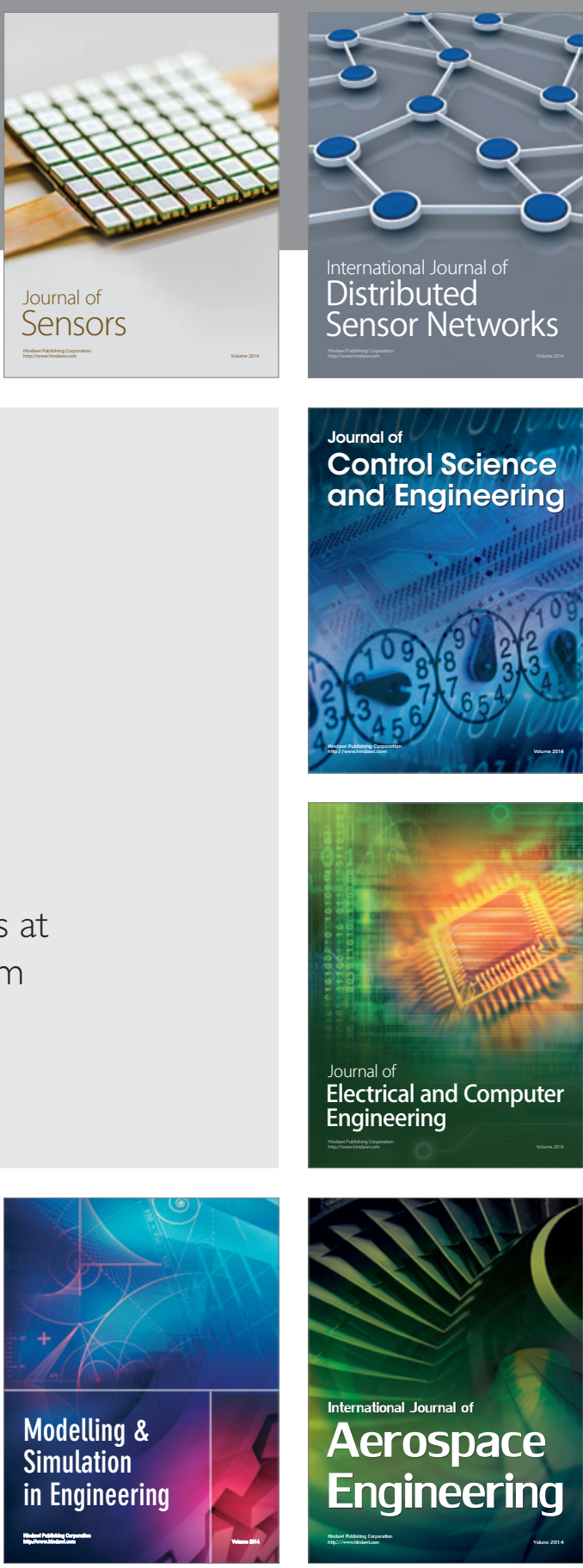

International Journal of

Distributed

Sensor Networks

Journal of

Control Science

and Engineering
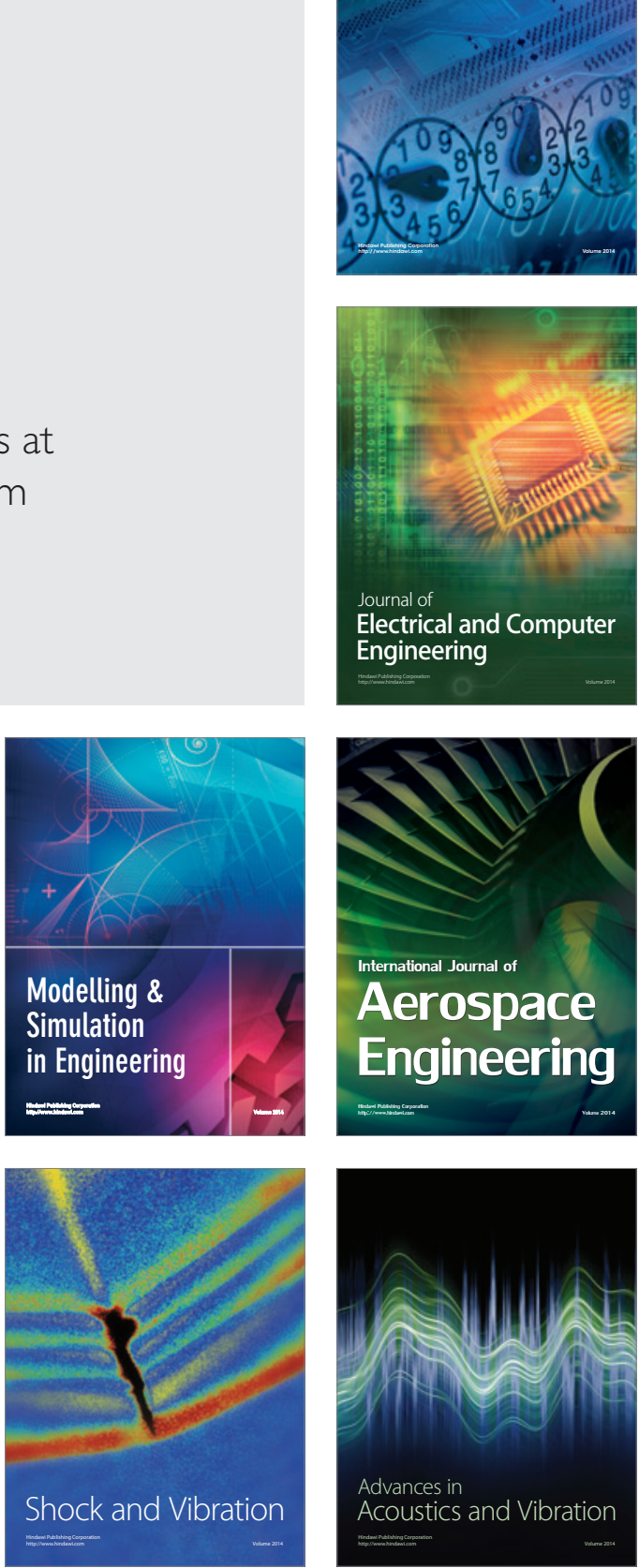